\title{
Temporal Dynamics of Attention during Encoding versus Maintenance of Working Memory: Complementary Views from Event-related Potentials and Alpha-band Oscillations
}

\author{
Nicholas E. Myers*, Lena Walther*, George Wallis, Mark G. Stokes**, \\ and Anna C. Nobre**
}

\begin{abstract}
Working memory (WM) is strongly influenced by attention. In visual WM tasks, recall performance can be improved by an attention-guiding cue presented before encoding (precue) or during maintenance (retrocue). Although precues and retrocues recruit a similar frontoparietal control network, the two are likely to exhibit some processing differences, because precues invite anticipation of upcoming information whereas retrocues may guide prioritization, protection, and selection of information already in mind. Here we explored the behavioral and electrophysiological differences between precueing and retrocueing in a new visual WM task designed to permit a direct comparison between cueing conditions. We found marked differences in ERP profiles between the precue and retrocue
\end{abstract}

\section{INTRODUCTION}

Visual working memory (WM) is known to be malleable by selective attention (Gazzaley \& Nobre, 2011; Nobre \& Stokes, 2011; Awh, Vogel, \& Oh, 2006; Postle, 2006; Oberauer, 2002). In partial-report paradigms, the presentation of a selective cue preceding the onset of the memory array ("precue") effectively reduces memory load, leading to improved performance. Importantly, selective cues presented after encoding ("retrocues"; Pertzov, Bays, Joseph, \& Husain, 2012; Griffin \& Nobre, 2003; Landman, Spekreijse, \& Lamme, 2003), during the maintenance delay, can also improve performance. As with precues, retrocues increase the probability of accurate recall (Murray, Nobre, Clark, Cravo, \& Stokes, 2013; Williams, Hong, Kang, Carlisle, \& Woodman, 2012; Murray, Nobre, \& Stokes, 2011), possibly by shifting the cued item into a more robust representational format (Rerko, Souza, \& Oberauer, 2014; Oberauer, 2013; Rerko \& Oberauer, 2013; Sligte, Scholte, \& Lamme, 2008). Prioritization in WM may rely on similar mechanisms as in anticipatory attention (Chun, Golomb,

University of Oxford

*These authors made equal contributions to this study.

**These authors made equal contributions to this study. conditions. In line with precues primarily generating an anticipatory shift of attention toward the location of an upcoming item, we found a robust lateralization in late cue-evoked potentials associated with target anticipation. Retrocues elicited a different pattern of ERPs that was compatible with an early selection mechanism, but not with stimulus anticipation. In contrast to the distinct ERP patterns, alpha-band (8-14 Hz) lateralization was indistinguishable between cue types (reflecting, in both conditions, the location of the cued item). We speculate that, whereas alpha-band lateralization after a precue is likely to enable anticipatory attention, lateralization after a retrocue may instead enable the controlled spatiotopic access to recently encoded visual information.
\& Turk-Browne, 2011; Chun, 2011). To chart the possible commonalities and differences in anticipatory and retrospective shifts of attention, we compared the dynamics of spatial attention mechanisms triggered by precues and retrocues using EEG.

Research on the neural effects of anticipatory spatial cues has revealed a number of ERPs that reflect the orienting of attention in space. Broadly, they have been grouped into early potentials related to processing the cue and shifting attentional focus (see Methods for an introduction of the early potentials used in this study) and later potentials related to anticipation. Among later potentials (beyond $500 \mathrm{msec}$ after cue onset), the late directing attention-related positivity (LDAP; Murray et al., 2011; Eimer, Forster, \& van Velzen, 2003; Hopf \& Mangun, 2000; Harter, Miller, Price, LaLonde, \& Keyes, 1989) has been linked to anticipatory processing of the upcoming task-relevant stimulus. Similarly, the lateralization of alpha-band oscillations has been hypothesized to regulate visual excitability in specific regions of cortex so that anticipated information at an attended location can receive prioritized processing (Jensen \& Mazaheri, 2010; Worden, Foxe, Wang, \& Simpson, 2000; Foxe, Simpson, \& Ahlfors, 1998; but see Pfurtscheller, Stancák, \& Neuper, 1996). One possibility is that directed 
alpha-band lateralization leads to the preferential routing of attended visual input into higher-level areas through changes in excitability of the underlying neural population (Jensen, Bonnefond, \& VanRullen, 2012).

Compared with anticipatory cueing, the neural consequences of retrocueing are much less explored. The behavioral effects of retrocues are generally of comparable magnitude as those of precues, and retrocues activate a similar frontoparietal control network (Chun et al., 2011; Nobre et al., 2004). Moreover, retrocues share some of the early ERP markers of precues (Griffin \& Nobre, 2003), and retrospective cues have been shown to modulate activity in visual regions involved in the encoding of WM information (Kuo, Stokes, Murray, \& Nobre, 2014; Munneke, Belopolsky, \& Theeuwes, 2012; Kuo, Yeh, Chen, \& D'Esposito, 2011; Sligte, Scholte, \& Lamme, 2009; Lepsien \& Nobre, 2006). Nevertheless, there may still be substantial differences in the attention-related neural mechanisms triggered by retrocues compared with precues.

In contrast to the effects on control networks and ERPs, the effect of retrocues on neural oscillations and on posterior alpha oscillations in particular is unknown. During WM maintenance, a number of studies have shown posterior alpha power increases (Spitzer \& Blankenburg, 2012; Haegens, Osipova, Oostenveld, \& Jensen, 2010; Jensen, Gelfand, Kounios, \& Lisman, 2002; Klimesch, Doppelmayr, Schwaiger, Auinger, \& Winkler, 1999). The increase in posterior alpha power during WM delays has been interpreted as an active inhibitory process designed to limit interference from distracting visual information (Bonnefond \& Jensen, 2012; Sauseng et al., 2009). Anticipatory cueing studies typically require the selection of a visual stimulus. In contrast, studies finding WM-related alpha power increases either presented nonvisual material for rehearsal (such as vibrotactile stimuli, which do not require processing in visual cortex; Spitzer \& Blankenburg, 2012; Haegens et al., 2010), or they employed a verbal WM task (Sternberg, 1966), which requires the rehearsal of letter strings. In the latter task, once visual information has been transformed into a phonological code, visual cortex presumably becomes task-irrelevant. It is unclear whether alpha power also increases in a task encouraging storage of information as a visual code and how retrocues would then modulate alpha power.

We were interested in testing whether comparing the oscillatory responses to anticipatory and retrospective shifts of attention can arbitrate between different models of how retrocues improve WM. The improvement could be achieved (1) by maintaining spatial attention toward the cued location, possibly in anticipation of the probe. In this case, retrospective cues would lead to a contralateral decrease in alpha power, similar to what is observed after an anticipatory cue and possibly reflecting probe anticipation. Alternatively, (2) it could arise through protection from interference by inhibiting currently irrelevant locations. This should lead to a relative increase in contralateral alpha power to limit interference. Finally, (3) transient access to the cued item and recoding into a preferred representational format (such as the "focus of attention"; see Oberauer, 2013; Cowan, 2000) may be the cause of retrocueing benefits. In this case, a temporary decrease in alpha power might suffice to allow access to areas storing cued information before it is transformed into a different representational state.

We examined this question using a novel task design that allowed us to address these possibilities. In the past, task design has complicated direct comparisons of the neural mechanisms involved in precue and retrocue processing, because many studies have not controlled for some important nuisance factors. For one, precues have tended to appear earlier in the trial sequence (before presentation of the memory array) than retrocues (after presentation of the memory array; see Nobre et al., 2004; Griffin \& Nobre, 2003). Because the two cue types have appeared at different times within a trial sequence, serial position in the trial complicates the interpretation of any differences. In addition to aiding retrieval, retrocues may have conferred a behavioral advantage by increasing anticipatory attention toward the probe. This effect could contribute to the activity increase in frontoparietal control regions that is seen both in precueing and retrocueing. In the current study, we adapted the task design to compare modulatory mechanisms evoked by precues and retrocues. The current design equates all aspects of stimulus presentation between cueing conditions, so that only the nature of the attention shift (anticipatory or retrospective) differs between cue types. A spatial cue, presented at the same serial position in every trial, could increase the relevance of either (a) one of two items presented in a previous array (in the retrocue condition) or (b) one of two memory items from an upcoming second array (precue).

We analyzed ERPs linked to attentional selection (see Methods) and to sustained anticipatory attention (LDAP). When target information was already accessible to attentional selection (i.e., after retrocues, but not precues), we examined early potentials linked to attentional target selection and alpha-band lateralization in response to the different cue types. We predicted that early potentials might be similar for prospective and retrospective cues, reflecting attentional orienting to a cued spatial location. In contrast, we predicted that the LDAP and alpha lateralization would show differences between conditions, because they have been associated primarily with stimulus anticipation. Prospective cues, where relevant information is still forthcoming, might lead to a stronger LDAP and alpha lateralization than retrospective cues, where relevant information has already been retrieved and must be protected from upcoming interference. We hoped to use these results to inform different theories of prioritization in WM and about the possible functions of alpha oscillations more generally.

Our results revealed some unexpected effects, shedding light on common as well as distinct mechanisms of anticipatory and retrospective attention shifts. We found ERP 
responses to be largely in line with our hypotheses: We observed early lateralized ERP responses to both cue types, whereas an EEG marker of anticipatory attention (LDAP) robustly differentiated between retro- and prospective cues. In addition, early stimulus-evoked processing (P1) was attenuated after a retrocue and amplified after a precue, especially contralateral to the cued side. Surprisingly, this occurred although the spatiotopic response of alpha synchronization was identical in anticipatory and retrospective attention to WM items. The unexpected alpha-band response to retrocues favors the interpretation that alphaband lateralization during retrocueing may reflect access to spatiotopically stored information, rather than perceptual anticipatory attention.

\section{METHODS}

\section{Participants}

We tested 24 healthy volunteers between the ages of 18 and 35 years on a sequential VSTM task (Figure 1A). Data from six participants contained too many eye movements or blinks to be analyzed (more than $50 \%$ of trials), leaving data from 18 participants (age range $=19-33$ years, 11 women) in the final analysis.

\section{Precision WM Task}

We collected EEG data while participants performed a precision visual WM task (see Bays \& Husain, 2008). The task was modified to include the presentation of a spatial cue between two serially presented memory arrays (see Figure 1A). Participants viewed two arrays, each containing two peripherally presented oriented bars, separated by a spatial or neutral cue, and were subsequently required to judge whether a probe appearing at a previously occupied location was rotated clockwise or counterclockwise. Each trial contained a total of four memory items, each presented in a separate quadrant of the screen. Spatial retrocues (toward a location in the first array) and precues (toward a location in the upcoming second array) indicated
Figure 1. Task design and behavioral results. (A) Example trial structure. Each trial began with the onset of a fixation cross, followed by the display of a memory array consisting of two oriented bars. Participants remembered the orientation of each bar. After a 800-msec delay, a cue appeared. Informative cues could point to a quadrant that had contained an item in the first array (retrocues) or to a previously unoccupied quadrant (precues). The cued item was probed in $70 \%$ of trials. Uninformative (neutral) cues gave no information about which item would be cued. Following the cue, a second array appeared, with two items in previously unoccupied quadrants. After a further delay, a probe stimulus appeared at the location of one of the previous stimuli. The probe appeared at the same location but was rotated clockwise or counterclockwise (relative to the probed memory item). The magnitude of rotation changed from trial to trial and ranged from $2^{\circ}$ to $39^{\circ}$. Participants judged the direction of rotation and received visual feedback in the form of a green (correct response) or red (incorrect) fixation dot during the intertrial interval (not shown). (B) Behavioral performance. Each panel shows the proportion of clockwise responses as a function of the magnitude and direction of the relative probe rotation (angular change), separately for valid, neutral, and invalid cues (the invalid condition corresponds to trials probing an uncued item from the respective array, irrespective of whether the cue pointed to the other item in the same array or one of the items in the other array). When Array 1 was probed (retrocue trials; left), valid cues significantly improved accuracy, primarily by reducing guess rate (i.e., the offset between the asymptote of the sigmoid response function and 0 or 1 ). Memory precision (i.e., the slope of the function) was not significantly affected by cue validity. Precue trials (right) showed better performance overall, but the same effect of cue validity. Here, costs of invalid cues are also visible. Both plots show mean responses across all 18 observers. Error bars indicate SEM.
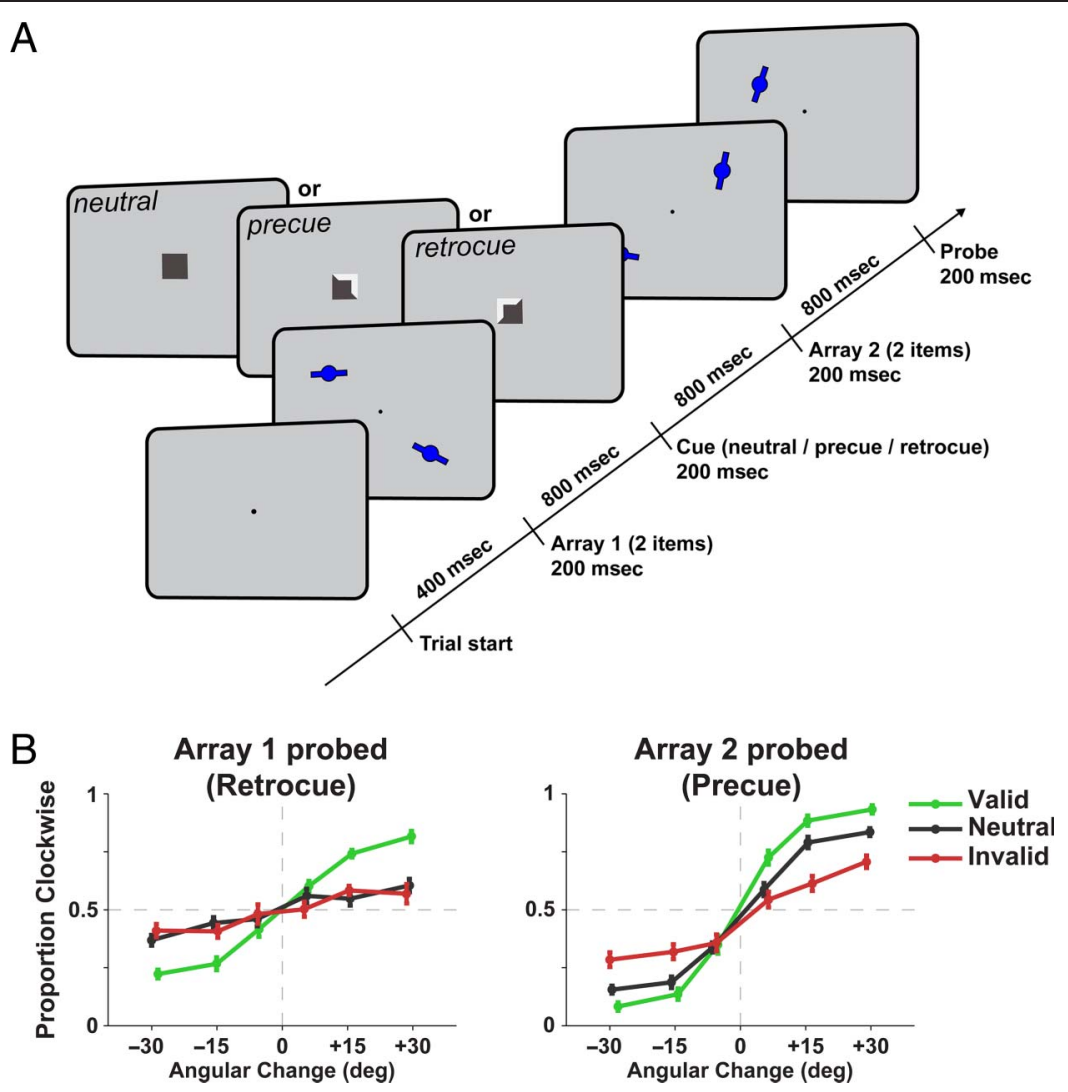
the item that was likely to be probed (with a validity of $70 \%)$. On invalidly cued trials, one of the other three items was probed (each with 33\% likelihood).

Each trial began with a fixation period (400 msec), followed by Memory Array 1 (presented for $200 \mathrm{msec}$ ). Each memory array consisted of two oriented bars (length $1.5^{\circ}$ visual angle, width $0.2^{\circ}$, with a small disc of $0.6^{\circ}$ diameter at the bar's center to denote the point of rotation). In each array, stimuli were centered in diagonally opposite quadrants of the screen (i.e., either the top left and bottom right quadrants or the top right and bottom left quadrants), at $5^{\circ}$ eccentricity from fixation. After an ISI of $800 \mathrm{msec}$, a cue appeared (200 msec). Neutral cues (a dark gray square of side length $0.4^{\circ}$ at fixation) were uninformative about which item would be probed. Spatial cues (a thin white border of $0.1^{\circ}$ along two adjacent edges of the gray cue square, forming an arrow pointing to one of the four quadrants) indicated the location of the item that would be probed (with a validity of $70 \%$ ). If the cued item had already been presented in Array 1, the cue acted as a retrocue. Alternatively, the cue acted as a precue if it indicated an item to be presented in Array 2. Memory Array 2 appeared (also for $200 \mathrm{msec}$ ) after cue offset and another ISI of $800 \mathrm{msec}$. To prevent spatial overlap across arrays, the two stimuli were presented in the two quadrants that were unoccupied in Array 1. After a further ISI of $800 \mathrm{msec}$, a probe stimulus appeared (for $200 \mathrm{msec}$ ) at the same location as one of the four memory items. The probe was an oriented bar similar to the item at that location but rotated relative to the original orientation. Participants made a binary response indicating whether the probe was rotated clockwise or counterclockwise, relative to the item at the probed location. We varied the rotation angle between memory and probe angles between $2^{\circ}$ and $39^{\circ}$. Rotation angles were binned into three categories: easy (rotation angles uniformly distributed between 21 and $\left.39^{\circ}\right)$, medium $\left(11-21^{\circ}\right)$, and hard $\left(2-11^{\circ}\right)$. The bins of the small and medium angles were narrower than the large angle bin to improve estimation of memory precision (see Behavioral Analysis) and to encourage participants to remember stimuli as accurately as possible. Responses were made using a mouse with a trackball that could be rotated clockwise or counterclockwise. Participants were explicitly encouraged to make use of cues to improve their accuracy. RT was not emphasized. Intertrial intervals were uniformly jittered between 1.25 and $1.75 \mathrm{sec}$, with an average duration of $1.5 \mathrm{sec}$.

Participants completed the experiment in one session after two practice blocks. The task consisted of ten 7-min blocks, each comprising 64 trials, for a total of 640 trials. Of these, 400 trials were cued (200 retrocue, 200 precue), and 240 trials were neutral (with 120 probing Array 1 and 120 probing Array 2), meaning that a cue was presented on $62.5 \%$ of trials. Of the 400 cued trials, 280 trials (140 retrocue, 140 precue) were validly cued. Participants sat in a dimly lit booth at a distance of $74 \mathrm{~cm}$ from the monitor (22-in. Samsung SyncMaster 2233, San Diego, CA; resolution $=1680 \times 1050$ pixels; refresh rate $=60 \mathrm{~Hz}$; screen width $=47 \mathrm{~cm}$ ). A chin rest was used to help participants keep their heads still. Binocular gaze locations were continuously recorded with a desktop mount videobased eye tracker at $500 \mathrm{~Hz}$ (EyeLink 1000, SR Research, Ontario, Canada), allowing for offline detection of blinks and saccades. All trials in which gaze deviated from the central fixation dot by more than $1.5^{\circ}$ were discarded. Participants were instructed to fixate on the center of the screen at all times and not to blink during trials. Eyetracker data from three participants were too noisy for analysis. In these cases, we relied on the electrooculogram data for blink and saccade detection (see below).

\section{Behavioral Analysis}

In a first step, we used a three-way repeated-measures ANOVA on response accuracy to test the effects of Array probed (Array 1, Array 2), Cue validity (valid, neutral, invalid), and Trial difficulty (easy [21-39 rotation angle], medium $\left[11-21^{\circ}\right]$, hard $\left.\left[2-9^{\circ}\right]\right)$. In a second step, we made use of the variable trial difficulty to test the effects of cue validity and array on the likelihood of correct recall and the precision of memory. We assumed that observers would respond at random on trials where they had no memory of the probed item, whereas on remembered trials, they would respond with Gaussian variability. Therefore, we used a mixture model (Zhang \& Luck, 2008), consisting of a uniform distribution (to account for the proportion of random guesses) and a von Mises distribution (to account for the precision of remembered responses). We fit a model with two free parameters:

$$
\begin{aligned}
& P(\text { correct } \mid \Delta)=(1-\text { pGuess }) * \operatorname{vonMises}(\Delta, \mu, \kappa) \\
& \quad+\text { pGuess } / 2 ;
\end{aligned}
$$

where $P($ correct $\mid \Delta)$ is the probability of a correct response given a probe that is rotated $\Delta$ degrees relative to the remembered stimulus and vonMises is the cumulative von Mises distribution (i.e., the circular analogue of the normal distribution, which can be evaluated numerically) with mean $\mu$ (fixed at 0 ) and precision $\kappa$ (proportional to the inverse of the standard deviation), evaluated at $\Delta$. pGuess determines asymptotic performance (i.e., the guess rate or proportion of random responses). Estimates of memory precision ( $\kappa$ ) and guess rate (pGuess) were then compared across conditions using a repeated-measures ANOVA with factors Cue validity and Array probed.

\section{EEG Acquisition}

The EEG was recorded continuously with NuAmp amplifiers (Neuroscan, Inc., Albany, CA) from $40 \mathrm{Ag} / \mathrm{AgCl}$ electrodes. Electrodes were positioned according to a subset of the 10-10 international system (AEEGS, 1991). Recordings were taken from the following electrodes: $\mathrm{Fz}, \mathrm{FCz}, \mathrm{Cz}, \mathrm{CPz}, \mathrm{Pz}$, 
POz, Oz, FP1/2, F3/4, F5/6, FC3/4, FC5/6, C3/4, C5/6, CP3/4, $\mathrm{CP} 5 / 6, \mathrm{P} 3 / 4, \mathrm{P} 5 / 6, \mathrm{PO} 3 / 4$, PO7/8, O1/2. Blinks and eye movements were monitored by deriving bipolar recordings from an electrode placed below the right eye and FP2 (vertical EOG) and from electrodes placed near the outer canthi of each eye (horizontal EOG). The electrode in position $\mathrm{AFz}$ was used as the ground. The right mastoid was used as the active reference. Recordings were also taken from the left mastoid to derive an average-mastoid reference offline. Electrical impedance was kept below $5 \mathrm{k} \Omega$, and activity was filtered with a low-pass filter of $300 \mathrm{~Hz}$. The analogueto-digital sampling rate of the brain activity was set at $1000 \mathrm{~Hz}$, and data were recorded continuously for the entire experiment.

\section{EEG Processing}

Processing and EEG analyses were done offline, using the EEGLAB toolbox (Delorme \& Makeig, 2004) and custom Matlab scripts for preprocessing. First, the EEG was rereferenced to the average of the left and right mastoid and bandpass-filtered between 0.1 and $40 \mathrm{~Hz}$ (using a second-order Butterworth filter). We bandpass-filtered the horizontal EOG and vertical EOG data between 1 and $40 \mathrm{~Hz}$ and smoothed the filtered time series with a sliding boxcar window of 11-msec length to remove brief spikes that were not related to eye movements. Next, the EEG and EOG were segmented into epochs ranging from $1600 \mathrm{msec}$ before the cue (600 msec before the first stimulus array) to $3000 \mathrm{msec}$ after the cue (1000 msec after the onset of the probe stimulus). We automatically rejected trials with EOG amplitudes outside $\pm 75 \mu \mathrm{V}$ surrounding Array 1 ( -200 to $+400 \mathrm{msec})$, the cue $(-200$ to $+1600 \mathrm{msec})$, Array $2(-1200$ to $+600 \mathrm{msec})$, or the probe $(-200$ to $+600 \mathrm{msec})$. We used eyetracking data (see above) and the horizontal EOG to eliminate trials with saccades to the stimuli. Finally, all epochs were visually inspected for any further artifacts. For ERP analyses of cue- and array-locked potentials, we baseline-corrected the data using a short interval before the onset of the event of interest (200 msec before cue onset and $50 \mathrm{msec}$ before onset of Array 2). The shorter baseline period before onset of Array 2 was chosen to minimize any potential effect of late, slow potentials evoked by the cue. When calculating lateralization measures, on trials with a right-hand cue, we flipped the channel topography along the midline to obtain an index of lateralization (contra- versus ipsilateral to the cue). On neutral trials, we flipped the topography if the probed item was on the right.

\section{ERP Analyses}

One of the earliest potentials showing cue-dependent lateralization is the early directing attention negativity (EDAN; Harter et al., 1989). It has been interpreted as a consequence of attentional orienting toward a relevant spatial location (Murray et al., 2011; Hopf \& Mangun, 2000; Nobre,
Sebestyen, \& Miniussi, 2000; Yamaguchi, Tsuchiya, \& Kobayashi, 1994; Harter et al., 1989), although in some cases, it may also reflect the selection of relevant features of the cue stimulus itself (van Velzen \& Eimer, 2003). The latter interpretation of the EDAN parallels that of another lateralized potential - the posterior contralateral N2 (N2pc, Eimer, 1996; or posterior contralateral negativity [PCN], e.g., Töllner, Müller, \& Zehetleitner, 2012). The N2pc (or PCN) is elicited when a target item is identified and selected from a spatially distributed array (Woodman \& Luck, 1999, 2003; Hopf, Boelmans, Schoenfeld, Heinze, \& Luck, 2002; Eimer, 1996; Luck \& Hillyard, 1994). Much like the EDAN, it consists of an accentuated negative potential over posterior contralateral electrodes. The EDAN is usually succeeded in time by the anterior directing attention negativity (ADAN; Green \& McDonald, 2006; Praamstra, Boutsen, \& Humphreys, 2005; Eimer, Velzen, \& Driver, 2002), which is another lateralized component that has been associated with the controlled deployment of spatial attention (e.g., van Velzen \& Eimer, 2003). This component is usually observed over frontal sensors, peaking approximately between 300 and 500 msec after a cue (e.g., Kelly, Gomez-Ramirez, \& Foxe, 2009).

We averaged trials separately for the three conditions of interest (retrocue, precue, or neutral) and used $3 \times$ 2 ANOVAs with factors Cue type (retrocue, precue, neutral) and Side (contralateral, ipsilateral) to test for the effects of cueing and of lateralization in a number of potentials, defined a priori based on previous literature testing anticipatory cueing effects (Murray et al., 2011; Hopf \& Mangun, 2000; Nobre et al., 2000). Relative to the cue, we tested the N1 (150-180 msec after cue onset, at PO7/8), the N2 (240-300 msec, PO7/8, i.e., the N2pc or PCN), the EDAN (250-350 msec, PO7/8, O1/2; Hopf \& Mangun, 2000; Mangun, 1994), the ADAN (350-500 msec, FC3/4 and C3/4), and the LDAP (750-1000 msec, PO7/8 and O1/2). On neutral trials, lateralization was calculated relative to the side of the probed item.

Relative to Array 2, we were interested in the early visual response of the P1 (60-140 msec after array onset, tested at $\mathrm{PO} 7 / 8$ and $\mathrm{O} 1 / 2$ ). We also tested for more persistent effects on encoding by examining the amplitude of the N1 (150-180 msec) and P2 (300-400 msec) potentials as well as lateralization in the N2 window (N2pc, 240-300 msec, $\mathrm{PO} 7 / 8)$.

\section{Analysis of Alpha Power Lateralization}

To test for the effects of cues on desynchronization in the alpha band (8-14 Hz) and in surrounding frequencies, we decomposed the broadband signal over six occipitalparietal sensors (O1/2, PO7/8, P5/6) using Hanning tapers (window width 5 cycles), estimated at $0.5-\mathrm{Hz}$ steps between 5 and $20 \mathrm{~Hz}$ (using custom Matlab scripts and the Fieldtrip Toolbox; Oostenveld, Fries, Maris, \& Schoffelen, 2011). After $\log$ transforming $\left(10 \times \log _{10}\right)$ the power at each frequency, we baseline-corrected single-trial data by 
subtracting the average power in the 200 msec preceding the onset of Array 1 (i.e., $1200 \mathrm{msec}$ before cue onset). We then averaged power across bins in the alpha range (8-14 Hz) and averaged separately across contralateral and ipsilateral sensors (relative to the cued side on cue trials or relative to the probed side on neutral trials) at each time point after cue onset. We then calculated contra- and ipsilateral alpha power, averaged between 500 and 1000 msec after cue onset (i.e., up to the onset of Array 2), and tested for effects of Lateralization and of Cue type in a $2 \times 3$ ANOVA.

\section{Quadrant-specific Analysis of Alpha Power}

The preceding analysis only tested for lateralization of alpha power following a cue to the left or to the right. However, cues were directed at a specific quadrant, warranting a more detailed analysis of the topographical distribution of alpha power. Specifically, we reasoned that the pattern of alpha desynchronization might be specific to the cued quadrant, rather than the entire hemifield. In this task, the spatial specificity of alpha desynchronization could carry additional importance because the uncued quadrant (of the cued hemifield) always contained a (previously seen or an upcoming) distractor. To test this hypothesis, we used an encoding model to estimate the topographical pattern of alpha power desynchronization following visual stimulation in each quadrant and applied this model to the cue-induced alpha power topographies to estimate the specificity of desynchronization for the cued quadrant. Conceptually, this analysis is identical to encoding models that have been used to estimate information about the orientation, color, or shape of a stimulus, using fMRI (Serences \& Saproo, 2012; Brouwer \& Heeger, 2009, 2011; Naselaris, Kay, Nishimoto, \& Gallant, 2011) or EEG (Garcia, Srinivasan, \& Serences, 2013).

For each trial in the experiment (i.e., the test trial), we used a general linear model (fit to all other trials in the experiment, i.e., the training trials) to estimate the topographical distribution of alpha power evoked by a probe presented in each of the four quadrants (using neutral and valid cue trials together and averaging over $8-14 \mathrm{~Hz}$ and 200-800 msec after probe onset, when the effect was strongest). We solved the general linear model via ordinary least squares:

$$
\mathrm{W}=\mathrm{B}_{1} \mathrm{C}_{1}^{\prime}\left(\mathrm{C}_{1} \mathrm{C}_{1}^{\prime}\right)^{-1}
$$

where $\mathrm{C}_{1}$ is the design matrix ( 4 regressors $\times$ no. of training trials, with each regressor set to 1 for all trials with a probe in the corresponding quadrant and set to 0 otherwise), $\mathrm{B}_{1}$ is the training data set (probe-evoked alpha power at 35 EEG sensors $\times$ no. of training trials), and $\mathrm{W}$ is the estimated weight matrix (35 sensors $\times 4$ regressors/ quadrants). Given that the absolute power in a given frequency band might have differed across sensors, variability in power across the topography could have decreased the sensitivity of this analysis. However, a control analysis using a fifth, constant regressor to model out the mean at each sensor yielded nearly identical results. Therefore, differences in power between sensors were ignored in the subsequent analyses.

We used $\mathrm{W}$ to estimate the quadrant-wise activation in the test trial, $\mathrm{B}_{2}(35$ sensors $\times 1$ trial $)$ :

$$
\mathrm{C}_{2}=\left(\mathrm{W}^{\prime} \mathrm{W}\right)^{-1} \mathrm{~W}^{\prime} \mathrm{B}_{2}
$$

where $\mathrm{C}_{2}$ is the "activation" (in arbitrary units) in each quadrant. For each trial, we then sorted this activation relative to the cued quadrant. This procedure was repeated (using the same weight matrix W) for each time point in the trial and each frequency (between 5 and $20 \mathrm{~Hz}$ ) before moving to the next iteration in the leave-one-out procedure. We then used a $2 \times 4$ ANOVA with factors Cue type (precue, retrocue) and Quadrant (cued, same hemifield, opposite hemifield, and diagonally opposed) to test for cue-evoked quadrant-specific activation after the onset of Array 1, the cue, Array 2, and the probe. Furthermore, we classified the cued quadrant on each trial, time point, and frequency (using a simple voting procedure that assigned a quadrant label according to the regressor with the highest activation level) to test the accuracy of the model. We compared classification accuracy to chance (25\%) using one-sample $t$ tests. To assess the effects of cueing, we also used a window-of-interest approach by averaging the classification accuracy from 8 to $14 \mathrm{~Hz}$ and from 500 to $1000 \mathrm{msec}$ after cue onset.

\section{RESULTS}

As a point of reference, Table 1 provides a schematic summary of all results described below.

\section{Behavioral Results}

We conducted a $3 \times 2 \times 3$ ANOVA (Figure 1B) on accuracy with factors Cue validity (valid, invalid, neutral), Array probed (Array 1, Array 2), and Probe difficulty (hard, medium, easy). We found significant main effects of Cue validity $\left(F(2,34)=36.660, p=3.3 \times 10^{-9}\right)$, Array $(F(1,17)=64.076$, $\left.p=3.6 \times 10^{-7}\right)$, and Difficulty $(F(2,34)=76.028, p=2.8 \times$ $\left.10^{-13}\right)$, as well as significant interactions between Cue validity and Array $(F(2,34)=7.389, p=.002)$, Cue type and Difficulty $\left(F(4,68)=7.663, p=3.70 \times 10^{-5}\right)$, and Array and Difficulty $(F(2,34)=3.599, p=.038)$. The threeway interaction between Cue validity, Array, and Difficulty was also significant $(F(4,68)=3.882, p=.007)$.

Given the significant three-way interaction, we conducted post hoc analyses to test whether both precues (Array 2 probed) and retrocues (Array 1 probed) individually affected accuracy. For trials on which Array 1 was probed ("retrocue" trials), we found significant effects of 
Table 1. Summary of Behavioral and Neural Cueing Effects

\begin{tabular}{|c|c|c|c|c|c|c|c|c|c|c|c|}
\hline & \multirow{2}{*}{\multicolumn{2}{|c|}{ Behavior }} & \multirow{2}{*}{\multicolumn{4}{|c|}{ ERPs (Cue) }} & \multicolumn{2}{|c|}{ Alpha-band Effects } & \multirow{2}{*}{\multicolumn{3}{|c|}{ ERPs (Array 2) }} \\
\hline & & & & & & & & Ouadrant-has & & & \\
\hline & Recall Rate & Precision & $N 1 / N 2 p c$ & $E D A N$ & $A D A N$ & $L D A P$ & Lateralization & Desynchronization & $P 1$ & $N 2 p c$ & $P 2$ \\
\hline Retrocue & + & ns & + & + & + & $n s$ (rev.) & + & + & red. & $n s$ (rev.) & red. \\
\hline Precue & + & $n s$ & ns & + & $n s$ & + & + & + & + & ns & + \\
\hline
\end{tabular}

$+=$ a significant effect; $n s=$ no effect; red./rev. = a significant reduction or reversal of an effect, respectively (marginally significant effects in parentheses).

Cue validity $\left(F(2,34)=17.77, p=5.1 \times 10^{-6}\right)$ and Difficulty $\left(F(2,34)=20.40, p=1.5 \times 10^{-6}\right)$, along with a significant interaction $(F(4,68)=3.50, p=.012)$. This confirmed (a) that retrocues improved accuracy and (b) that the cueing benefit was largest on the easiest trials ( $t$ test comparing valid retrocues with neutral trials for easy probes: $t(17)=$ $6.51, p=5.4 \times 10^{-6}$, Cohen's $d=1.82$; medium probes: $t(17)=4.08, p=7.8 \times 10^{-4}, d=1.33$; difficult probes: $t(17)=1.49, p=.153, d=0.49)$. Compared with neutral cues, invalid retrocues (i.e., trials probing a noncued item from Array 1) did not decrease performance ( $t$ test neutral against invalid cues, $t(17)<1, p>.40$ for all three difficulties). However, this null result does not imply that invalid retrocueing carries no cost, as accuracies were sufficiently low (neutral: $57.7 \%$, invalid: $55.7 \%$ ) to have produced a floor effect. We found a similar (but stronger, given the three-way interaction) pattern of results when Array 2 was probed ("precue" trials; effect of Cue validity: $F(2$, $34)=37.72, p=2.3 \times 10^{-9}$; effect of Difficulty: $F(2,34)=$ $57.97, p=1.1 \times 10^{-11}$; interaction: $F(4,68)=8.75, p=$ $\left.9 \times 10^{-6}\right)$. In addition to the graded increase in effect size on valid trials (in line with the interaction between Cue validity and Difficulty, valid cues showed a larger benefit on easier trials, i.e., easy: $t(17)=7.53, p=8.19 \times 10^{-7}$, $d=0.94$; medium: $t(17)=3.87, p=.001, d=0.83$; difficult: $t(17)=2.79, p=.006, d=0.70)$, here we also saw significant costs of invalid cues (i.e., trials probing a noncued item from Array 2) on easy and medium difficulty trials (invalid vs. neutral; easy: $t(17)=-4.13, p=.0007, d=0.99$; medium: $t(17)=-5.76, p=2.3 \times 10^{-5}, d=1.79$; hard: $t(17)=$ $-0.71, p=.488, d=0.22$ ). These results confirm our behavioral hypotheses that both valid precues and retrocues significantly improve accuracy, in spite of the baseline accuracy differences between Arrays 1 and 2. In other words, retrocues (to items in Array 1) improve memory in spite of interference (from items in Array 2).

We used a model-based approach to dissociate whether cueing affected the precision or recall rate of remembered items. We found that cueing affected only the guess rate $(F(1,17)=7.81, p=.002)$, with no significant effect on precision $(\kappa, p=.987)$, indicating that cues primarily improved the likelihood of recalling an item, but not its fidelity. The probed array also affected guess rate $(F(2,34)=$ $17.4, p<.001)$, but not precision $(p=.705)$. However, there was a significant interaction between Cue validity and Probed array on precision $(F(2,34)=3.676, p=$ .036). The interaction reflected a significant difference in precision on valid trials probing either the first or second array $(t(17)=2.635, p=.0174)$ that was not present on neutral or invalid trials $(p=.380$ and $p=.445$, respectively). Thus, validly cued items presented in the second array were more likely to be recalled, and they were recalled with higher precision than items in Array 1. Given these differences in performance between arrays, we investigated the cueing effect separately for Array 1 (retrocues) and Array 2 (precues). Retrocue validity significantly improved guess rate $(F(2.34)=3.98, p=.028, t$ test valid vs. neutral: $t(17)=3.43, p=.003)$, but not precision $(p=.256)$. Similarly, precues affected only guess rate $(F(2.34)=7.255$, $p=.002, t$ test valid vs. neutral: $t(17)=4.17, p=.0006)$ but not precision $(p=.152)$.

\section{Event-related Responses to the Cue}

We next examined cue-evoked lateralization of the ERP as a marker of spatially directed attention to previous or upcoming information (Figure 2). We examined the well-known ERP markers of directed attention: EDAN, ADAN, and LDAP. In addition, we tested for modulation of the N2pc (or PCN) related to spatiotopic mechanisms of target selection.

In general, we found that both retrocues and precues modulated markers of attentional orienting. The EDAN was present after both retrocues and precues $(t(17)=$ $-7.06, p<.0001$ for retrocues, $t(17)=-2.23, p=.04$ for precues, $p=.28$ for neutral), although it was significantly stronger after a retrocue (Side $\times$ Cue type interaction $F(2,34)=12.33, p<.001)$. The intermediate stage ADAN was not strongly modulated by either cue type $(t(17)=$ $-2.33, p<.05$ for retrocues, $t(17)=-1.44, p=.16$ for precues, $p>.90$ for neutral, Side $\times$ Cue type interaction $p>.20)$. In contrast, the LDAP, immediately preceding the onset of the second array (250-0 msec prestimulus), showed lateralization for both retrocues and precues, but in opposite directions. Whereas precues showed a modest relative contralateral positivity $(t(17)=2.35, p=.031)$, retrocues exhibited a relative contralateral negativity $(t(17)=$ $-2.417, p=.027)$, resulting in a significant interaction between Side and Cue type in the interval from 750 to $1000 \operatorname{msec}(F(2,34)=11.17, p=.004)$. In addition, we 
saw a main effect of Cue type $(F(1,17)=10.07, p=.006)$. This main effect was driven by more negative potentials after precues: although retrocue and neutral trials did not differ $(F(1,17)=1.01, p=.33)$, there was a difference in potential between precue and neutral trials $(F(1,17)=11.04$, $p=.004)$. The difference between precues and retrocues was strongest over ipsilateral sensors $(t(17)=4.21, p=$ $.0006)$, with only a trend for a difference at contralateral sites $(t(17)=2.02, p=.06)$.

Returning to the earliest processing stage, we also found attentional orienting effects that were specific to retrocues. The N1 was significantly lateralized after a retrocue (paired $t$ test contra- vs. ipsilateral sensors, $t(17)=$ $-4.39, p=.0004)$, but not after precues or neutral cues $(p>.38$ for both, Side $\times$ Cue type (retro/precue) interaction $F(2,34)=4.45, p<.05)$. Likewise, the N2pc was modulated only after a retrocue $(t(17)=-4.03, p=$ $.0009, p>.20$ for precues and neutral, Side $\times$ Cue type interaction $F(2,34)=6.60, p<.05)$.

\section{Event-related Responses to Array 2}

Regarding the response to the second stimulus array (Figure 3), we predicted that both items would be attended on neutral trials, the cued item would be attended on precue trials, and no items would be attended on retrocue trials. We found that this prediction was borne out in the magnitude and lateralization of the $\mathrm{P} 1$ response, occurring 60-140 msec after stimulus onset. The ANOVA revealed a main effect of Cue type $(F(2,34)=6.74, p=.003)$ and a significant interaction with Side $(F(2,34)=7.56$, $p=.002)$, indicating that cue types affected P1 magnitude differentially at contra- and ipsilateral sensors. Whereas precues led to the expected contralateral P1 enhancement (paired $t$ test, $t(17)=2.51, p=.022$ ), retrocues attenuated the P1 contralateral to the cued side $(t(17)=-3.06$, $p=.007)$. Neutral trials did not show any lateralization $(t(17)=0.41, p=.689)$. Overall, the P1 was smaller on retrocue trials than on precue or neutral trials $(t(17)=-3.03$, $p=.008$ for retrocue vs. precue, $t(17)=-3.01, p=.008$ for retrocue vs. neutral), with no significant difference between precue and neutral P1 $(t(17)=0.94, p=.363$, precue-neutral). In summary, the P1 amplitude reduction is in line with the hypothesis that retrocues suppress processing of the second array. Furthermore, the reduction of the P1 contralateral to the cue indicates an additional, selective suppression in processing of new items in the retrocued hemifield.

We tested how these effects carried forward by analyzing the P1-N1 amplitude difference. We again saw a main effect of cue type $(F(2,34)=9.33, p=.001)$ that appeared to be driven by a reduction of the P1-N1 amplitude on retrocued trials $(t$ test compared with neutral, $t(17)=$ $-3.67, p=.002, t(17)=-4.48, p=.0003$ on contralateral and ipsilateral sensors, respectively). The P1-N1 amplitude was not lateralized in either cue condition $(p>.30$ for retrocues and precues). N1 amplitude itself (150$180 \mathrm{msec})$ was not modulated by cue type $(F(2,34)=$ $1.19, p=.318)$ or by side $(F(2,34)=0.12, p=.730)$, with no interaction $(F(2,34)=1.72, p=.194)$.
Figure 2. ERP responses to the cue. (A). Grand-averaged potential time courses taken from visual sensors $(\mathrm{O} 1 / 2$, PO7/8, see top left topography in B for locations). Visual ERPs showed modulations by both retrocues (top) and precues (middle), lateralizing in response to the cued side (contralateral sensors: dark lines, ipsilateral: gray lines). Neutral cues did not elicit any lateralization. The three shaded areas indicate time ranges used to calculate topographies and bar plots in (B) and (C). (B) Average lateralization topographies at times of interest in the N1 (left column), EDAN (middle column), and LDAP (right column) ranges. Topographies show difference between potentials after left cues and right cues (Left minus Right). (C) Bar plots showing mean potentials at times and sensors $(\mathrm{C}=$ contralateral; $\mathrm{I}=$ ipsilateral) of interest. Error bars indicate SEM.

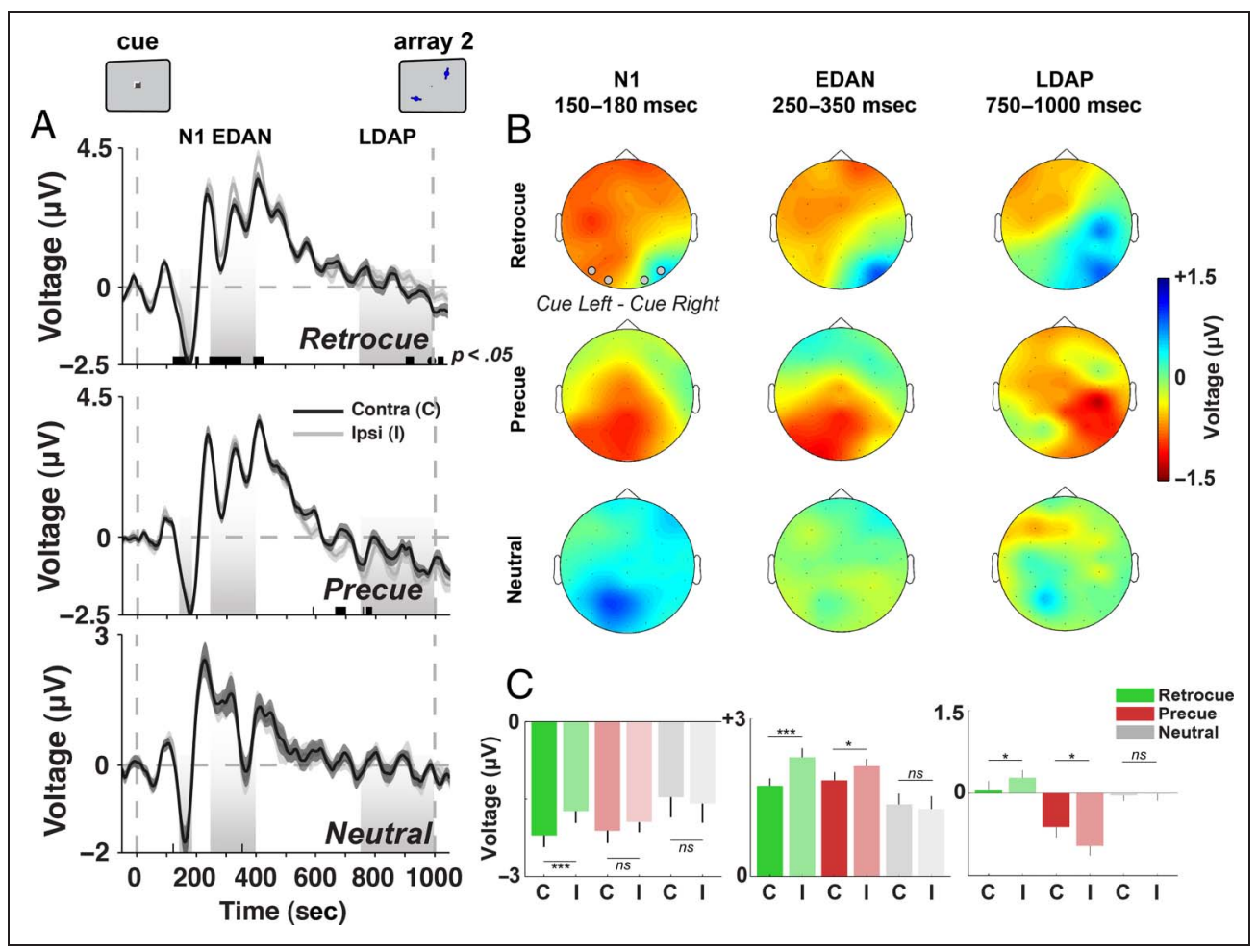


Figure 3. ERP responses to Array 2. (A) Grand-averaged potential time courses taken from visual sensors $(\mathrm{O} 1 / 2$, $\mathrm{PO} 7 / 8$, see top left topography in B). After retrocues, visual responses ( $\mathrm{P} 1$ and $\mathrm{P} 2)$ were attenuated, and P1 was lower at contralateral (dark lines) compared with ipsilateral sites (gray lines). Conversely, precues showed a contralateral increase in P1 amplitude. Shaded areas indicate the time range used to calculate topographies and bar plots in (B) and (C). (B) Average lateralization topographies at times of interest in the P1 (left column) and P2 (right column) ranges. Topographies show difference between potentials after left cues and right cues (Left minus Right) for the $\mathrm{P} 1$ and average potential for the P2. (C) Bar plots showing mean potentials at times and sensors $(\mathrm{C}=$ contralateral; $\mathrm{I}=$ ipsilateral) of interest. Sensors of interest $(\mathrm{P} 1$ : O1/2, PO7/8, P2: P3/4/5/6, $\mathrm{CP} 3 / 4 / 5 / 6)$ are indicated on the topographies in the top row. Error bars indicate SEM.

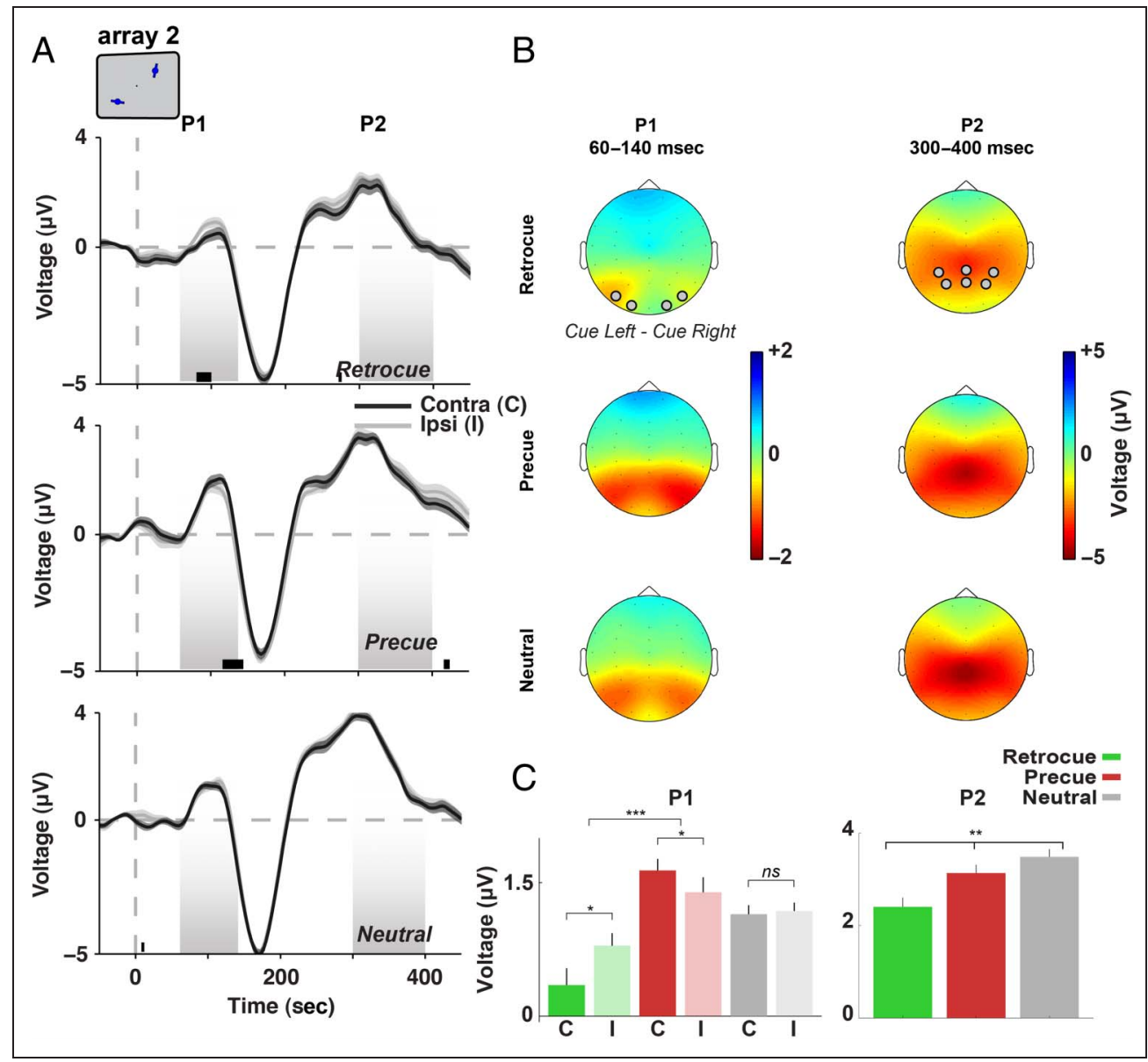

Next, we examined potentials in the N2 range (240$300 \mathrm{msec}, \mathrm{PO} 7 / 8$ ). We saw no strong evidence for lateralization: although there was a main effect of Cue type $(F(2$, $34)=10.349, p=.002)$, there was no main effect of Cued side $(F(1,17)=2.692, p=.119)$ and no interaction between Side and Cue type $(F(2,34)=1.400, p=.260)$. A paired $t$ test between contra- and ipsilateral potentials after precues showed no significant lateralization $(t(17)=$ $-0.289, p=.776)$. After retrocues, following the inverted P1 effect, there was a trend toward a contralateral negativity $(t(17)=-2.043, p=.054)$.

Finally, the P2 (over PO7/8 and O1/2), occurring between 300 and 400 msec after onset of the array, also showed a main effect of Cue type $(F(2,34)=8.11, p=.001)$. P2 magnitude over more central-parietal sensors (P3/4/5/6, CP3/4/ $5 / 6)$ showed the same pattern $(F(2,34)=6.08, p=.006)$. In both cases, the magnitude was highest for neutral trials, followed by precue trials. There was no significant P2 lateralization in the central-parietal ROI $(F(1,17)=1.04, p=$ .323 over central-parietal cortex), but we did see a main effect of Cue side over visual cortex $(F(1,17)=5.10$, $p=.037)$. The effect over visual cortex $(\mathrm{PO} 7 / 8, \mathrm{O} 1 / 2)$ did not correspond with significant lateralization in any one cue condition (contra minus ipsi difference, $t(17)=$ $-1.59, p=.129, t(17)=-1.20, p=.247, t(17)=-1.11$, $p=.284$, for retrocue, precue, and neutral trials, respec- tively) and no significant interaction $(F(2,34)=0.16$, $p=.850)$.

\section{Cue Effects on Alpha Power}

Overall, the onset of pre-, retro-, and neutral cues led to a temporary desynchronization in the alpha band for roughly $400 \mathrm{msec}$ (see time courses in Figure 4B). Between 500 and 1000 msec after the cue (leading up to Array 2), alpha power gradually rose again. On spatial cue trials, this rebound coincided with a divergence in power between contralateral and ipsilateral sensors (Figure $4 \mathrm{~B}$, main effect of side, $F(1,17)=13.66, p=.002$ ), leading to a significant lateralization both on retrocue trials $(t(17)=-3.19, p=.005)$ and precue trials $(t(17)=$ $-3.19, p=.005)$, but not on neutral trials $(t(17)=0.08$, $p=.93$, interaction Side $\times$ Cue type: $F(2,34)=3.39$, $p=.045)$. Although the relative decrease in contralateral alpha power after a precue confirmed our hypothesis, we did not expect to see the same pattern after a retrocue (because contralateral alpha could have increased to inhibit processing of the upcoming stimulus in Array 2 to protect the cued item). This similarity of alpha lateralization stands in contrast to the marked differences between cue types found in the ERP during the same time period (i.e., the LDAP in the 500 msec leading up to Array 2). 
Figure 4. Cue-evoked changes in posterior alpha power (8-14 Hz) after spatial retrocues and precues. (A) Topographic distribution of alpha power. Top row shows effects of retrocues after the cue (i.e., preceding the onset of Array 2) and before the onset of the probe. Bottom row shows effects of precues in the same time range. Colors indicate power change (relative to prestimulus baseline, in decibels). (B) Alpha power time courses at posterior sensors (O1/2, PO7/8, P5/6) between cue onset and probe onset. Each plot contains time courses of contralateral (dark lines) and ipsilateral (light gray) power, separated by cue condition (retrocue/neutral/ precue). Black lines at bottom indicate time points of significant lateralization (contralateral minus ipsilateral, $p<.05$ ). The bottom right plot shows lateralization (contra-ipsi) time courses for the three cue conditions. Green and red lines show time points of significant lateralization for retrocues and precues, respectively. Shaded areas indicate SEM.

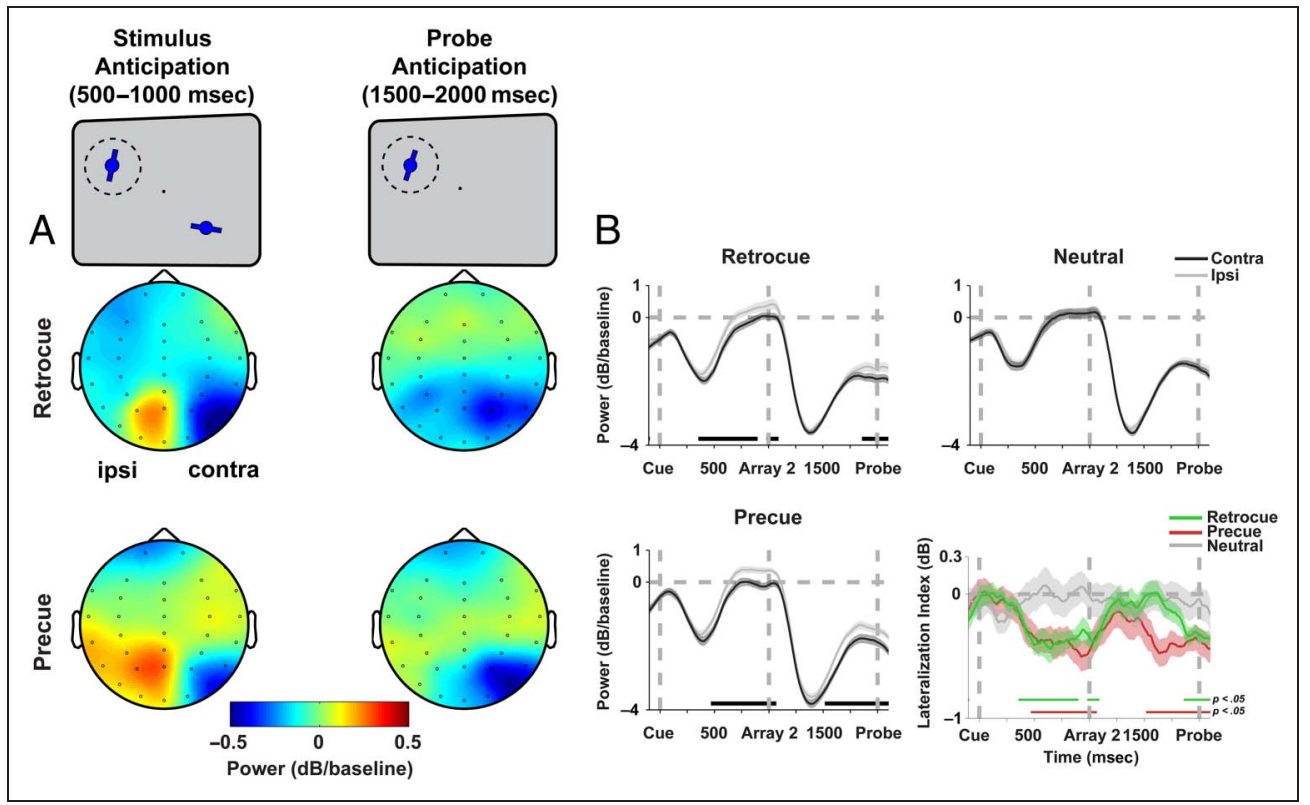

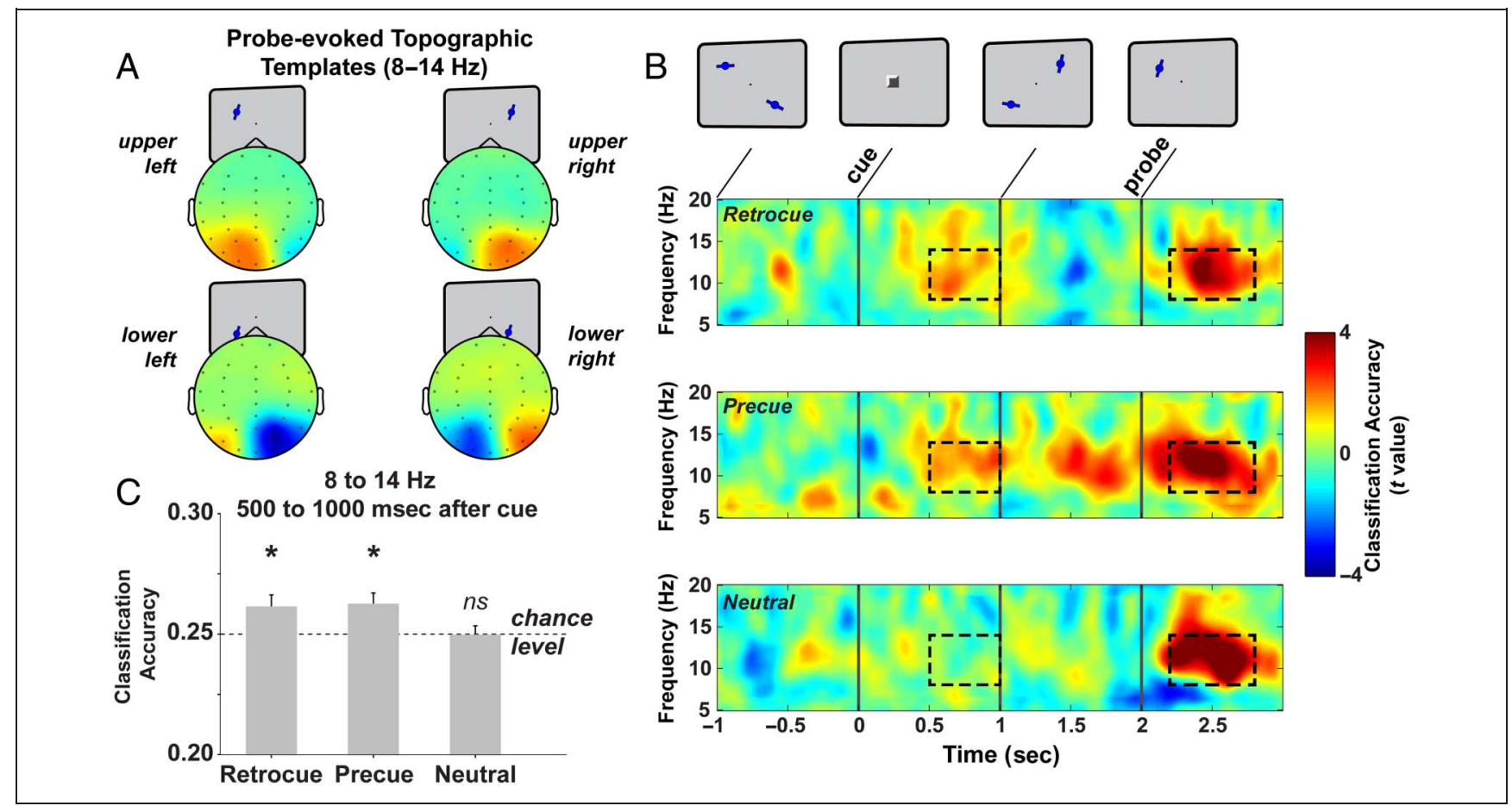

Figure 5. Quadrant decoding using alpha band power ( $t$ test vs. chance, 25\%). For each trial, we calculated the 8-14 Hz topographies evoked by probe onset on all other trials, separately for probes presented in the four screen quadrants. (A) shows the topographies, averaged across all trials and all participants. For illustration, the average topography has been subtracted from each quadrant-specific topography. The topography of the left-out test trial was then calculated at each frequency and time point in the trial and regressed against the four template topographies. The stimulus quadrant corresponding to the best-fitting topography was voted to have evoked the pattern on the test trial and was compared with the actually cued quadrant (or probed quadrant on neutral trials) to calculate classification accuracy. (B) shows $t$ statistic maps of classification accuracy (one-sample $t$ tests against 25\%, computed at each time point and frequency), smoothed using a 3-point moving average. Dashed windows after cue onset in (B) correspond to the data shown in (C). (C) Bar plots of classification accuracy per condition, averaged across 8-14 Hz, 500-1000 msec, after cue onset. For both cue types, quadrant was classified above chance $(* p<.05$, $n s=$ not significant $)$. 
Cue-related lateralization was quenched by the onset of the second stimulus array but then reemerged in the $250 \mathrm{msec}$ immediately before probe onset (main effect of Side, $F(1,17)=9.336, p=.007)$, between 1750 and $2000 \mathrm{msec}$ after the cue. Again, both cue types were significantly lateralized during this preprobe interval (retrocues: $t(17)=-2.36, p=.03$; precues: $t(17)=-2.81$, $p=.01$; neutral: $t(17)=-0.59, p=.56)$. On precue trials, this effect emerged earlier, beginning $500 \mathrm{msec}$ before onset of the probe (lateralization 500-250 msec before probe onset, $t(17)=-3.01, p=.008, p>.70$ for retrocue and neutral trials). For both cue types, the cue-induced alpha-band lateralization was restricted to parietal-occipital sensors (Figure 4A).

We additionally examined whether cued lateralization (as measured by alpha-band lateralization or the LDAP) related to behavioral improvements after retrocues or precues. We used the model-estimated cueing benefit (i.e., the difference in recall rate between cueing and neutral conditions) to test for Pearson correlations (across participants) with LDAP magnitude and the magnitude of cueevoked alpha lateralization (contralateral minus ipsilateral power). We found a significant correlation between alphaband lateralization after retrocues and the difference in recall rate between retrocues and neutral trials $(r=-.474$, $p=.0469)$, indicating that, when alpha power was more lateralized (more negative), the improvement in recall rate (after retrocues) was greater. However, this correla- tion was only significant at an uncorrected statistical level, and we found no other correlations with behavior (all uncorrected $p>$.078). This result should therefore be interpreted with some caution, particularly because our sample size $(N=18)$ may have been sufficient to show robust within-subject statistics, but fairly low for betweensubject correlation.

\section{Quadrant-specific Activation in the Alpha Band}

The topographical distribution of alpha power in response to the probe (8-14 Hz, 200-800 msec after onset) reliably distinguished the spatial location of the probe stimulus in all three cue conditions (see Figure 5A, dashed windows after probe onset, classification accuracy against chance level: $p<.001$ for neutral $(t(17)=5.93)$, valid precue $(t(17)=5.74)$, and valid retrocue trials $(t(17)=4.28))$ Using a leave-one-out procedure, we used this time (200$800 \mathrm{msec}$ after probe onset) and frequency (8-14 Hz) window to train quadrant-specific topographies (Figure 5A) that were then applied to the test trial at all time points and frequencies $(5-20 \mathrm{~Hz})$. Quadrant classification after cue onset (Figure 5C; 500-1000 msec after cue onset, 8-14 Hz; see also dashed windows after cue onset in Figure $5 \mathrm{~B})$ was significant on both retrocue $(t(17)=2.41$, $p=.028)$ and precue trials $(t(17)=2.84, p=.011)$, but not on neutral trials $(t(17)=-0.06, p=.953)$. In addition, on precue trials we were able to decode the
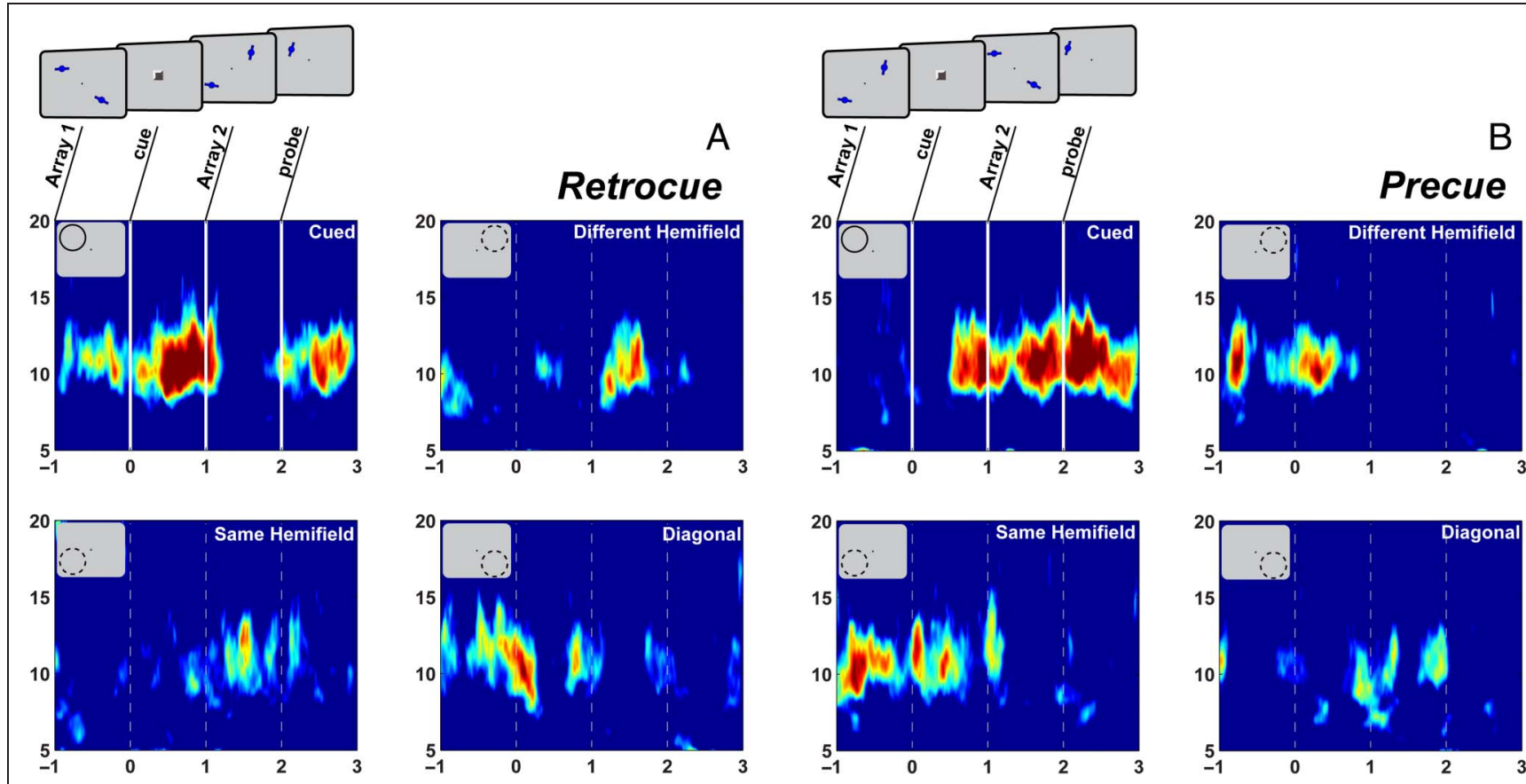

Figure 6. Quadrant-specific activation in the alpha band. (A) Retrocues elicit quadrant-specific shifts in alpha power. Each of the four timefrequency plots shows the correspondence of average topographies with the probe-evoked pattern, separately for each time point (from onset of Array 1 to $1 \mathrm{sec}$ after the probe) and frequency (5-20 Hz). The top left plot shows correlations with topographies evoked by a probe in the cued quadrant, with the other three plots showing correlations with topographies evoked by probes in the three uncued quadrants (separately for probes in the cued hemifield and in the two quadrants of the opposite hemifield). Color indicates correlation strength (in arbitrary units), with warmer colors indicating a better fit. (B) Quadrant-specific topographic patterns in response to precues. 
cued quadrant in the period leading up to the probe (15002000 msec after cue onset, $t(17)=3.64, p=.002, p>$ .50 on retrocue and neutral trials). The latter effect accompanies the earlier reemergence of alpha lateralization after Array 2 on precue trials (Figure 4E). The analysis described below, examining quadrant-specific activation, may elucidate why, on retrocue trials, alpha lateralization did seem to appear just before probe onset (1750-2000 msec after the cue; Figure 4B, F), although we were not able to classify the cued quadrant in this epoch using the decoding approach.

To examine the quadrant specificity of the analysis further, we separated the activation in the cued quadrant and the three uncued quadrants (in the same hemifield, the opposite hemifield, and the diagonally opposite corner) on retrocue and precue trials (Figure 6).

At a basic level, our analysis revealed predicted quadrantspecific patterns during periods of visual stimulation. In other words, the activation time courses followed the stimulus sequence. On retrocue trials (Figure 6A), activation in the two quadrants in which stimuli had appeared in Array 1 (i.e., the cued and diagonally opposed quadrants) preceded cue onsets (when stimuli were presented in these locations), whereas the two remaining quadrants showed activity after onset of the second array (when stimuli were presented there). Conversely, precue trials showed the opposite activation time course (Figure 6B). Here, activation in response to the second array emerged in the cued and, to a lesser extent, diagonally opposed quadrants, whereas the remaining quadrants showed activation preceding the cue. These time courses indicate that our analysis was sensitive enough to detect the stimulus sequence in each trial type. Furthermore, they suggest why retrocued quadrants could not be decoded leading up to the probe: because the stimuli in the second array led to alpha-band activation in the uncued quadrants, they may have counteracted the spatial specificity of the retrocue-based activation in the cued quadrant (without necessarily reducing the more basic lateralization effect).

We again saw reliable activation in the cued quadrant after probe onset and after cue onset (500-1000 msec) that was limited to the alpha band. Importantly, for the post-cue epoch (500-1000 msec), we saw a main effect of Quadrant $(F(3,51)=5.83, p=.002)$, but no effect of Cue type (precue/retrocue, $F(1,17)=0.243, p=.63$ ) and no interaction $(F(3,51)=0.216, p=.89)$. When we restricted our analysis to the two quadrants within the cued hemifield, we saw the same pattern (main effect of Quadrant: $F(1,17)=10.220, p=.005$; main effect of Cue type: $F(1,17)=0.002, p=.97$; interaction: $F(1$, $17)=0.521, p=.48)$. The robust activation difference between quadrants of the same hemifield confirms that shifts in alpha power were indeed specific to a cued quadrant, rather than a cued hemifield. In addition, our analysis shows that both precues and retrocues led to indistinguishable quadrant-specific reductions in alpha power.

\section{DISCUSSION}

We used a novel task in which a cue occurring within an equivalent temporal and spatial context triggers either anticipatory or retrospective shifts of attention during WM. Our main finding is that retrospective attention shifts lead to a relative contralateral decrease in posterior alpha-band power. Importantly, cued alpha lateralization was temporary rather than sustained, potentially constraining theories of how top-down prioritization operates in WM. The findings point to a mechanism of transient access to visually selective populations, whereas selected WM information is transformed into a more robust representational state. Before discussing this mechanism, we will lay out the consequences of retrospective attention shifts on behavior and on ERP markers to constrain the interpretation of the alpha-band results.

\section{Behavioral Impact of Cueing in WM}

Cues conferred behavioral benefits for both precued and retrocued items (Griffin \& Nobre, 2003; Landman et al., 2003) by increasing the likelihood of recalling the correct item (also see Murray et al., 2011, 2013). The precision of memory representations was not modulated by either cue type. Prior studies using free recall of probed features have found that precues significantly improve both the rate of recall and precision (e.g., Bays, Gorgoraptis, Wee, Marshall, \& Husain, 2011; Gorgoraptis, Catalao, Bays, \& Husain, 2011; Zokaei, Gorgoraptis, Bahrami, Bays, \& Husain, 2011). The likelihood of correct recall seems to be robustly improved by both precues and retrocues, irrespective of the mode of assessment. By contrast, the forced-choice design of the current study may not have been sensitive enough to measure cue-evoked changes in precision.

Although the behavioral improvement because of precues and retrocues was similar, we found that overall performance was significantly higher for items from the second array. Presumably, performance for Array 1 was lower because of the interfering effect of Array 2 (Zanto \& Gazzaley, 2009). This asymmetry in difficulty may have induced a difference in motivation that could explain some of the discrepancies in the ERP results: Because performance was comparatively high on precue trials, participants may have used the cues less (or at least differently) and still achieved a high level of performance. Nonetheless, precues induced both accuracy benefits and costs (on infrequent invalid trials), demonstrating that observers were using them to their advantage.

\section{ERP Markers Point to Processing Differences between Retrospective and Prospective Attention Shifts}

Within the first 500 msec of cue processing, both prospective and retrospective cues led to the lateralization of 
potentials that have been associated with shifts of spatial attention. Retrocues had a strong effect on the EDAN (250-350 msec after the cue) and also modulated the ADAN (350-500 msec), indicating a rapid refocusing of attention (Brignani, Lepsien, Rushworth, \& Nobre, 2009; Kiss, Jolicœur, Dell'Acqua, \& Eimer, 2008). In addition, retrocues may also have prompted the rapid selection of the cued target from WM (Kuo, Rao, Lepsien, \& Nobre, 2009), as indicated by even earlier lateralizations in the N1 (150-180 msec) and N2 (240-300 msec; i.e., N2pc) ranges.

Lateralization may have occurred more quickly after retrocues than precues because retrocues allowed for immediate selection from the contents of WM. Other studies have found variability in the time course of selection from WM, with some seeing markers of access in the N2 time range (Leszczyński, Myers, Akyürek, \& Schubö, 2012; Astle, Nobre, \& Scerif, 2010; Kuo et al., 2009), whereas others found that similar but slightly later components responded to cues directing attention in WM (Dell'Acqua, Sessa, Toffanin, Luria, \& Jolicour, 2010; Eimer \& Kiss, 2010). In the current study, the time pressure to complete selection before the onset of the second array (and the interference this likely caused) may have encouraged the relatively early shifts induced by retrocues.

Similar to retrocues, precues also showed a significant lateralization in the EDAN, in line with previous findings (van Velzen \& Eimer, 2003; Hopf \& Mangun, 2000; Nobre et al., 2000; Yamaguchi et al., 1994; Harter et al., 1989). However, the magnitude of the EDAN was significantly larger after retrocues than precues. Precues may have shown attenuated (and delayed) lateralization in this study for a number of reasons. First, observers may have used them less, because performance was already better on precue trials (see above). Second, a precue in the current study required more operations than in typical studies of anticipatory attention, because participants first had to parse whether the cue pertained to the previous or the upcoming array and possibly needed to suppress information about the first array before shifting attention.

Interestingly, ERP responses to precues and retrocues began to diverge between 500 and $1000 \mathrm{msec}$ after the cue, leading up to the onset of the second array. Whereas precues evoked the typical lateralized anticipatory response (LDAP), retrocues did not and even led to a brief but statistically significant reversal of this potential. The LDAP has been associated with the top-down deployment of anticipatory spatial attention, which should have improved encoding of relevant information on precue trials. On retrocue trials, none of the upcoming information was relevant (because the cued information had already been presented), and thus, one may have expected no anticipatory lateralization at all. The reversal of the LDAP may indicate a shift of attention away from the location of the retrocued item to reduce interference from the upcoming array. The transient nature of the effect (and the relatively modest statistical significance) may alternatively indicate that the LDAP did not play a large role in guiding attention in this task or that this late potential peaked at different time points in different participants, leading to a temporal smearing (and consequent reduction) of the effect. Another possibility is that this late negativity reflects contralateral delay activity, a sustained negative potential often observed in delay periods of WM tasks (Vogel \& Machizawa, 2004). In the current study, this negativity emerged only late after the cue and was not sustained. This makes it unlikely to reflect persistent maintenance of the cued information in WM, but this interpretation cannot be ruled out entirely.

We found that the visually evoked responses to the second memory array were also differentially modulated by precues and retrocues. Precues again led to the expected enhancement of processing, as indicated by an increase in P1 amplitude contralateral to the cued stimulus (Hillyard, Vogel, \& Luck, 1998). In contrast, retrocues led to an overall reduction in P1 amplitude and to a reduced P1 contralateral to the cued side. Similarly, the N2 also showed a main effect of cue type (although there was no strong evidence for lateralization in this interval, possibly because selection had already begun earlier). The slightly later P2 response was also smallest after retrocues, with increasing amplitudes on precue and neutral trials. This pattern points to a reduction in processing of the second array after retrocues, possibly to protect WM contents by reducing interference. The increasing amplitude of the P2 may also have reflected increased encoding demands after the second array on precue and neutral trials.

\section{Alpha-band Lateralization May Support Different Operations after Prospective and Retrospective Attention Shifts}

The main focus of our study lay on how alpha-band (8$14 \mathrm{~Hz}$ ) oscillations respond to retrocues and precues. Importantly, we expected the alpha-band responses to provide information about the neural mechanism of prioritization during WM maintenance. After both precues and retrocues, we found a contralateral, quadrant-specific desynchronization of posterior alpha-band power. Under both precues and retrocues, the quadrant-specific biasing of alpha power appears to reflect desynchronization over areas representing the cued quadrant, rather than increased synchronization in irrelevant areas. We draw this conclusion from the cross-comparison of the quadrantspecific, multivariate pattern evoked by the probe stimulus (which most likely led to a desynchronization in the alpha band). After retrocues, we found strong crossgeneralization only in the interval between the cue and Array 2.

On precue trials, the alpha-band lateralization coincided with other markers of increased excitability (the LDAP and an increased P1 amplitude to the subsequent array). Therefore, the precue alpha-band effects likely supported sustained attention toward the anticipated location of the cued stimulus. On retrocue trials, the alpha-band effect 
was not compatible with sustained anticipation. The ERP response to the second, irrelevant array was attenuated (especially contralateral to the cue). Also, lateralization was not sustained throughout the trial: The appearance of Array 2 eliminated the lateralization, and it only reemerged immediately before probe onset.

Our results could help arbitrate among several theories of how prioritization acts in WM. First, the results do not support a pure inhibition mechanism: Under an inhibition account, alpha-band power over irrelevant cortex would increase so that prioritized WM information is protected from interference (Sauseng et al., 2009). Several studies have argued that alpha power over currently task-irrelevant cortex increases to inhibit processing of distracting stimuli that could otherwise interfere with the contents of WM (Bonnefond \& Jensen, 2012; Haegens et al., 2010; Jensen et al., 2002; Klimesch et al., 1999). We may have expected to see a similar effect after a retrocue: Once the cued item has been selected for protection, alpha power could have increased, especially contralateral to the cued side, to reduce interference from the second array. Although we observed evidence for inhibition of the second array, we observed a contradictory pattern of alpha lateralization: a relative contralateral desychronization.

A second possible mechanism of WM prioritization is sustained attention (Chun, 2011; Chun et al., 2011; Awh et al., 2006). A sustained attention account would predict that retrocues improve memory by persistently increasing excitability at the anticipated probe location. This should have led to a sustained desynchronization contralateral to the cued (and eventually probed) location. However, we observed only a transient desynchronization, such that lateralization did not immediately reemerge after processing of the second array. Moreover, alpha lateralization did not lead to an overall increase in excitability (as measured by the response to Array 2). A recent study showing contralateral alpha-band desynchronization after a retrocue (Poch, Campo, \& Barnes, 2014) could be compatible with sustained attention. However, their design and analysis did not allow a distinction between the sustained attention account and a more transient mechanism. The authors did not examine the time course of desynchronization and so were not able to test whether lateralization was sustained or transient. Perhaps more importantly, there were no intervening events between cue and probe onset, making it difficult to dissociate sustained attention to the cued item from anticipatory attention toward the probe stimulus.

\section{Putative Role for Spatiotopic Alpha Shifts in Item-specific Access}

Our results appear to be most consistent with the idea that retrocues elicit short-term increases in activity in spatiotopic visual cortex. This could give control areas (such as $\mathrm{pFC}$ ) access to the population storing the cued visual features to move them into a more robust representational state (Chatham, Frank, \& Badre, 2014; Oberauer, 2013;
Lewis-Peacock \& Postle, 2012; Lewis-Peacock, Drysdale, Oberauer, \& Postle, 2012; Olivers, Peters, Houtkamp, \& Roelfsema, 2011; Sligte et al., 2008). Alpha-band desynchronization could either reflect increased local activity or communication between visual cortex and top-down control areas.

Recent studies into the mechanistic effects of alpha-band desynchronization have demonstrated that a decrease in alpha power primarily coincides with a gain in neural excitability. Alpha desynchronization has been shown to increase baseline (Bollimunta, Mo, Schroeder, \& Ding, 2011) and stimulus-evoked (Haegens, Nacher, Luna, Romo, \& Jensen, 2011) firing rates, the likelihood of perceiving two stimuli instead of one (Lange, Oostenveld, \& Fries, 2013) and, to some extent, the amplitude of the stimulus-evoked EEG response (P1; Rajagovindan \& Ding, 2011). We speculate that, after a retrocue, the selective desynchronization in the alpha-band results in a temporary spatiotopic increase in excitability for the cued item. The increased excitability presumably translates into enhanced retention for the cued feature information. This could occur by making the activity in the sensory area more resilient to decay (reducing the chances of sudden loss of feature information; Murray et al., 2013) or by involving control regions themselves in the representation of the cued feature. Alternatively, the observed alpha-band effects could be a consequence of increased local neural activity, which would lead to decreased alpha power specifically at the activated site. In either case, once the cued information has been accessed, there is no longer a need for sustained alpha lateralization, and it can return to baseline levels.

Methods capable of assessing local activity (either invasively or using gamma oscillations as a proxy) may be necessary to arbitrate between the two putative consequences of alpha lateralization outlined here. In addition, future studies will need to use longer delay periods to identify conclusively the temporal dynamics of alpha-mediated memory access when there is less time pressure from an imminent distractor array. Finally, neurodisruptive techniques (such as TMS) might also provide evidence of the functional role of alpha oscillations in the current task. For instance, TMS may affect only a cued item and only after alpha synchronization has shifted to prioritize it. Zokaei, Manohar, Husain, and Feredoes (2014) recently demonstrated that TMS to visual cortex disrupted the precision of WM items only after they had been cued. This specific disruption for preferred items might depend on a prior reduction in alpha power that sufficiently increases excitability, allowing TMS to have a larger effect. Examining the temporal dynamics of WM disruption could help arbitrate between the mechanisms outlined above.

Beyond the implications for WM, our results show that retrospective attention tasks may be used to illuminate the role of alpha oscillations in top-down prioritization separately from their role in anticipation. Although the alpha-band lateralization and the LDAP occur in the same time window, they appear to give different results 
after retrocues. The discrepancy might have occurred because the two markers reflect different operations that are decoupled in retrocueing, but not in precueing. Specifically, alpha lateralization after retrocues may not reflect anticipatory spatial attention shifts. This is particularly surprising in light of findings that, in anticipatory cueing tasks, alpha lateralization is correlated with ERP markers of anticipation (such as the LDAP; see Kelly et al., 2009) and with contralateral delay activity (see van Dijk, Van Der Werf, Mazaheri, Medendorp, \& Jensen, 2010; Mazaheri \& Jensen, 2008). Additionally, alpha lateralization usually predicts subsequent visual processing (Rajagovindan \& Ding, 2011) and visual excitability (Romei, Brodbeck, et al., 2008; Romei, Rihs, Brodbeck, \& Thut, 2008).

After retrocues, alpha-band lateralization and LDAP may reflect different neural operations, such as, for example, access to the cued part of sensory cortex (alpha-band desynchronization) versus facilitation of sensory processing of upcoming stimuli (LDAP). In summary, studies using retrospective attention shifts may prove fruitful in distinguishing the role of alpha oscillations in top-down attention from its role in anticipation.

\section{Conclusion}

We conclude that retrospective shifts of attention to items in WM trigger spatiotopic access to information reflected in early ERP markers of spatial attention shifts and lateralization of alpha-band power over visual cortex. Although alpha-band lateralization was similar after precues and retrocues, the size and lateralization of visual responses evoked by a WM array after the cue depended on the cue type. Our task design and the difference in ERPs to the second array make alternative mechanisms of retrocueing less probable: Neither sustained protection via distractor inhibition nor sustained spatial attention could easily account for our pattern of results. Nonetheless, the proposed transient spatiotopic access may occur on its own or in combination with a prospective shift of attention in anticipation of a probe stimulus. We speculate that the access operation may help shift prioritized information into a more robust representational format (Cowan, 2000), thus increasing the likelihood of correct recall. The successful ability to use top-down attentional control to prioritize relevant information is thus a crucial aspect of intelligent cognition and behavior.

Reprint requests should be sent to Nicholas E. Myers, Department of Experimental Psychology, University of Oxford, 9 South Parks Road, Oxford, United Kingdom, OX1 3UD, or via e-mail: nicholas.myers@psy.ox.ac.uk.

\section{REFERENCES}

AEEGS. (1991). American Electroencephalographic Society guidelines for standard electrode position nomenclature. Journal of Clinical Neurophysiology, 8, 200-202.
Astle, D. E., Nobre, A. C., \& Scerif, G. (2010). Subliminally presented and stored objects capture spatial attention. Journal of Neuroscience, 30, 3567-3571.

Awh, E., Vogel, E. K., \& Oh, S. H. (2006). Interactions between attention and working memory. Neuroscience, 139, 201-208.

Bays, P. M., Gorgoraptis, N., Wee, N., Marshall, L., \& Husain, M. (2011). Temporal dynamics of encoding, storage, and reallocation of visual working memory. Journal of Vision, $11,6$.

Bays, P. M., \& Husain, M. (2008). Dynamic shifts of limited working memory resources in human vision. Science, 321, 851-854.

Bollimunta, A., Mo, J., Schroeder, C. E., \& Ding, M. (2011). Neuronal mechanisms and attentional modulation of corticothalamic alpha oscillations. Journal of Neuroscience, 31, 4935-4943.

Bonnefond, M., \& Jensen, O. (2012). Alpha oscillations serve to protect working memory maintenance against anticipated distracters. Current Biology, 22, 1969-1974.

Brignani, D., Lepsien, J., Rushworth, M. F. S., \& Nobre, A. C. (2009). The timing of neural activity during shifts of spatial attention. Journal of Cognitive Neuroscience, 21, 2369-2383.

Brouwer, G. J., \& Heeger, D. J. (2009). Decoding and reconstructing color from responses in human visual cortex. Journal of Neuroscience, 29, 13992-14003.

Brouwer, G. J., \& Heeger, D. J. (2011). Cross-orientation suppression in human visual cortex. Journal of Neurophysiology, 106, 2108-2119.

Chatham, C. H., Frank, M. J., \& Badre, D. (2014). Corticostriatal output gating during selection from working memory. Neuron, 81, 930-942.

Chun, M. M. (2011). Visual working memory as visual attention sustained internally over time. Neuropsychologia, 49, 1407-1409.

Chun, M. M., Golomb, J. D., \& Turk-Browne, N. B. (2011). A taxonomy of external and internal attention. Annual Review of Psychology, 62, 73-101.

Cowan, N. (2000). The magical number 4 in short-term memory: A reconsideration of mental storage capacity. Behavioral and Brain Sciences, 24, 87-114, discussion 114-85.

Dell'Acqua, R., Sessa, P., Toffanin, P., Luria, R., \& Jolicour, P. (2010). Orienting attention to objects in visual short-term memory. Neuropsychologia, 48, 419-428.

Delorme, A., \& Makeig, S. (2004). EEGLAB: An open source toolbox for analysis of single-trial EEG dynamics including independent component analysis. Journal of Neuroscience Methods, 134, 9-21.

Eimer, M. (1996). The N2pc component as an indicator of attentional selectivity. Electroencephalography and Clinical Neurophysiology, 99, 225-234.

Eimer, M., Forster, B., \& van Velzen, J. (2003). Anterior and posterior attentional control systems use different spatial reference frames: ERP evidence from covert tactile-spatial orienting. Psychophysiology, 40, 924-933.

Eimer, M., \& Kiss, M. (2010). An electrophysiological measure of access to representations in visual working memory. Psychophysiology, 47, 197-200.

Eimer, M., Velzen, J. V., \& Driver, J. (2002). Cross-modal interactions between audition, touch, and vision in endogenous spatial attention: ERP evidence on preparatory states and sensory modulations. Journal of Cognitive Neuroscience, 14, 254-271.

Foxe, J. J., Simpson, G. V., \& Ahlfors, S. P. (1998). Parieto-occipital $\sim 10 \mathrm{~Hz}$ activity reflects anticipatory state of visual attention mechanisms. NeuroReport, 9, 3929-3933.

Garcia, J. O., Srinivasan, R., \& Serences, J. T. (2013). Near-real-time feature-selective modulations in human cortex. Current Biology, 23, 515-522. 
Gazzaley, A., \& Nobre, A. C. (2011). Top-down modulation: Bridging selective attention and working memory. Trends in Cognitive Sciences, 16, 129-135.

Gorgoraptis, N., Catalao, R. F. G., Bays, P. M., \& Husain, M. (2011). Dynamic updating of working memory resources for visual objects. Journal of Neuroscience, 31, 8502-8511.

Green, J. J., \& McDonald, J. J. (2006). An event-related potential study of supramodal attentional control and crossmodal attention effects. Psychophysiology, 43, 161-171.

Griffin, I. C., \& Nobre, A. C. (2003). Orienting attention to locations in internal representations. Journal of Cognitive Neuroscience, 15, 1176-1194.

Haegens, S., Nacher, V., Luna, R., Romo, R., \& Jensen, O. (2011). $\alpha$-Oscillations in the monkey sensorimotor network influence discrimination performance by rhythmical inhibition of neuronal spiking. Proceedings of the National Academy of Sciences, U.S.A., 108, 19377-19382.

Haegens, S., Osipova, D., Oostenveld, R., \& Jensen, O. (2010). Somatosensory working memory performance in humans depends on both engagement and disengagement of regions in a distributed network. Human Brain Mapping, 31, 26-35.

Harter, M. R., Miller, S. L., Price, N. J., Lalonde, M. E., \& Keyes, A. L. (1989). Neural processes involved in directing attention. Journal of Cognitive Neuroscience, 1, 223-237.

Hillyard, S. A., Vogel, E. K., \& Luck, S. J. (1998). Sensory gain control (amplification) as a mechanism of selective attention: Electrophysiological and neuroimaging evidence.

Philosophical Transactions of the Royal Society, Series B, Biological Sciences, 353, 1257-1270.

Hopf, J. M., Boelmans, K., Schoenfeld, A. M., Heinze, H. J., \& Luck, S. J. (2002). How does attention attenuate target-distractor interference in vision? Cognitive Brain Research, 15, 17-29.

Hopf, J. M., \& Mangun, G. R. (2000). Shifting visual attention in space: An electrophysiological analysis using high spatial resolution mapping. Clinical Neurophysiology, 111, 1241-1257.

Jensen, O., Bonnefond, M., \& VanRullen, R. (2012). An oscillatory mechanism for prioritizing salient unattended stimuli. Trends in Cognitive Sciences, 16, 200-206.

Jensen, O., Gelfand, J., Kounios, J., \& Lisman, J. E. (2002). Oscillations in the alpha band $(9-12 \mathrm{~Hz})$ increase with memory load during retention in a short-term memory task. Cerebral Cortex, 12, 877-882.

Jensen, O., \& Mazaheri, A. (2010). Shaping functional architecture by oscillatory alpha activity: Gating by inhibition. Frontiers in Human Neuroscience, 4, 1-8.

Kelly, S. P., Gomez-Ramirez, M., \& Foxe, J. J. (2009). The strength of anticipatory spatial biasing predicts target discrimination at attended locations: A high-density EEG study. European Journal of Neuroscience, 30, 2224-2234.

Kiss, M., Jolicœur, P., Dell'Acqua, R., \& Eimer, M. (2008). Attentional capture by visual singletons is mediated by top-down task set: New evidence from the N2pc component. Psychophysiology, 45, 1013-1024.

Klimesch, W., Doppelmayr, M., Schwaiger, J., Auinger, P., \& Winkler, T. (1999). "Paradoxical" alpha synchronization in a memory task. Cognitive Brain Research, 7, 493-501.

Kuo, B.-C., Rao, A., Lepsien, J., \& Nobre, A. C. (2009). Searching for targets within the spatial layout of visual short-term memory. Journal of Neuroscience, 29, 8032-8038.

Kuo, B.-C., Stokes, M. G., Murray, A. M., \& Nobre, A. C. (2014). Attention biases visual activity in visual Short-term Memory. Journal of Cognitive Neuroscience, 26, 1377-1389.

Kuo, B.-C., Yeh, Y. Y., Chen, A., \& D’Esposito, M. (2011). Functional connectivity during top-down modulation of visual short-term memory representations. Neuropsychologia, 49, 1589-1596.

Landman, R., Spekreijse, H., \& Lamme, V. A. F. (2003). Large capacity storage of integrated objects before change blindness. Vision Research, 43, 149-164.

Lange, J., Oostenveld, R., \& Fries, P. (2013). Reduced occipital alpha power indexes enhanced excitability rather than improved visual perception. Journal of Neuroscience, 33, 3212-3220.

Lepsien, J., \& Nobre, A. C. (2006). Attentional modulation of object representations in working memory. Cerebral Cortex, 17, 2072-2083.

Leszczyński, M., Myers, N. E., Akyürek, E. G., \& Schubö, A. (2012). Recoding between two types of STM representation revealed by the dynamics of memory search. Journal of Cognitive Neuroscience, 24, 653-663.

Lewis-Peacock, J. A., Drysdale, A. T., Oberauer, K., \& Postle, B. R. (2012). Neural evidence for a distinction between short-term memory and the focus of attention. Journal of Cognitive Neuroscience, 24, 61-79.

Lewis-Peacock, J. A., \& Postle, B. R. (2012). Decoding the internal focus of attention. Neuropsychologia, 50, 470-478.

Luck, S. J., \& Hillyard, S. A. (1994). Electrophysiological correlates of feature analysis during visual search. Psychophysiology, 31, 291-308.

Mangun, G. R. (1994). Orienting attention in the visual fields: An electrophysiological analysis. In Cognitive electrophysiology (pp. 81-101). Boston: Birkhäuser Boston.

Mazaheri, A., \& Jensen, O. (2008). Asymmetric amplitude modulations of brain oscillations generate slow evoked responses. Journal of Neuroscience, 28, 7781-7787.

Munneke, J., Belopolsky, A. V., \& Theeuwes, J. (2012). Shifting attention within memory representations involves early visual areas. PLoS One, 7, e35528.

Murray, A. M., Nobre, A. C., Clark, I. A., Cravo, A. M., \& Stokes, M. G. (2013). Attention restores discrete items to visual short-term memory. Psychological Science, 24, 550-556.

Murray, A. M., Nobre, A. C., \& Stokes, M. G. (2011). Markers of preparatory attention predict visual short-term memory performance. Neuropsychologia, 49, 1458-1465.

Naselaris, T., Kay, K. N., Nishimoto, S., \& Gallant, J. L. (2011). Encoding and decoding in fMRI. Neuroimage, 56, 400-410.

Nobre, A. C., Coull, J. T., Maquet, P., Frith, C. D., Vandenberghe, R., \& Mesulam, M. M. (2004). Orienting attention to locations in perceptual versus mental representations. Journal of Cognitive Neuroscience, 16, 363-373.

Nobre, A. C., Sebestyen, G. N., \& Miniussi, C. (2000). The dynamics of shifting visuospatial attention revealed by event-related potentials. Neuropsychologia, 38, 964-974.

Nobre, A. C., \& Stokes, M. G. (2011). Attention and short-term memory: Crossroads. Neuropsychologia, 49, 1391-1392.

Oberauer, K. (2002). Access to information in working memory: Exploring the focus of attention. Journal of Experimental Psychology: Learning, Memory, and Cognition, 28, 411-421.

Oberauer, K. (2013). The focus of attention in working memory-from metaphors to mechanisms. Frontiers in Human Neuroscience, 7, 1-16.

Olivers, C. N. L., Peters, J., Houtkamp, R., \& Roelfsema, P. R. (2011). Different states in visual working memory: When it guides attention and when it does not. Trends in Cognitive Sciences, 15, 327-334.

Oostenveld, R., Fries, P., Maris, E., \& Schoffelen, J.-M. (2011). FieldTrip: Open source software for advanced analysis of MEG, EEG, and invasive electrophysiological data. Computational Intelligence and Neuroscience, 2011, 1-9.

Pertzov, Y., Bays, P. M., Joseph, S., \& Husain, M. (2012). Rapid forgetting prevented by retrospective attention cues. 
Journal of Experimental Psychology: Human Perception and Performance, 39, 1224-1231.

Pfurtscheller, G., Stancák, A., Jr., \& Neuper, C. (1996). Event-related synchronization (ERS) in the alpha band-an electrophysiological correlate of cortical idling: A review. International Journal of Psychophysiology, 24, 39-46.

Poch, C., Campo, P., \& Barnes, G. R. (2014). Modulation of alpha and gamma oscillations related to retrospectively orienting attention within working memory. European Journal of Neuroscience, 40, 2399-2405.

Postle, B. R. (2006). Working memory as an emergent property of the mind and brain. Neuroscience, 139, 23-38.

Praamstra, P., Boutsen, L., \& Humphreys, G. W. (2005). Frontoparietal control of spatial attention and motor intention in human EEG. Journal of Neurophysiology, 94, 764-774.

Rajagovindan, R., \& Ding, M. (2011). From prestimulus alpha oscillation to visual-evoked response: An inverted-U function and its attentional modulation. Journal of Cognitive Neuroscience, 23, 1379-1394.

Rerko, L., \& Oberauer, K. (2013). Focused, unfocused, and defocused information in working memory. Journal of Experimental Psychology: Learning, Memory, and Cognition, 39, 1075-1096.

Rerko, L., Souza, A. S., \& Oberauer, K. (2014). Retro-cue benefits in working memory without sustained focal attention. Memory \& Cognition, 42, 712-728.

Romei, V., Brodbeck, V., Michel, C., Amedi, A., Pascual-Leone, A., \& Thut, G. (2008). Spontaneous fluctuations in posterior $\alpha$-band EEG activity reflect variability in excitability of human visual areas. Cerebral Cortex, 18, 2010-2018.

Romei, V., Rihs, T., Brodbeck, V., \& Thut, G. (2008). Resting electroencephalogram alpha-power over posterior sites indexes baseline visual cortex excitability. NeuroReport, 19, 203-208.

Sauseng, P., Klimesch, W., Heise, K. F., Gruber, W. R., Holz, E., Karim, A. A., et al. (2009). Brain oscillatory substrates of visual short-term memory capacity. Current Biology, 19, 1846-1852.

Serences, J. T., \& Saproo, S. (2012). Computational advances towards linking BOLD and behavior. Neuropsychologia, 50, 435-446.

Sligte, I. G., Scholte, H. S., \& Lamme, V. A. F. (2008). Are there multiple visual short-term memory stores? PLoS One, 3, e1699.

Sligte, I. G., Scholte, H. S., \& Lamme, V. A. F. (2009). V4 activity predicts the strength of visual short-term memory representations. Journal of Neuroscience, 29, 7432-7438.

Spitzer, B., \& Blankenburg, F. (2012). Supramodal parametric working memory processing in humans. Journal of Neuroscience, 32, 3287-3295.
Sternberg, S. (1966). High-speed scanning in human memory. Science, 153, 652-654.

Töllner, T., Müller, H. J., \& Zehetleitner, M. (2012). Top-down dimensional weight set determines the capture of visual attention: Evidence from the PCN component. Cerebral Cortex, 22, 1554-1563.

van Dijk, H., Van Der Werf, J., Mazaheri, A., Medendorp, W. P., \& Jensen, O. (2010). Modulations in oscillatory activity with amplitude asymmetry can produce cognitively relevant event-related responses. Proceedings of the National Academy of Sciences, U.S.A., 107, 900-905.

van Velzen, J., \& Eimer, M. (2003). Early posterior ERP components do not reflect the control of attentional shifts toward expected peripheral events. Psychophysiology, 40, 827-831.

Vogel, E. K., \& Machizawa, M. G. (2004). Neural activity predicts individual differences in visual working memory capacity. Nature, 428, 748-751.

Williams, M., Hong, S. W., Kang, M. S., Carlisle, N. B., \& Woodman, G. F. (2012). The benefit of forgetting. Psychonomic Bulletin E Review, 20, 348-355.

Woodman, G. F., \& Luck, S. J. (1999). Electrophysiological measurement of rapid shifts of attention during visual search. Nature, 400, 867-869.

Woodman, G. F., \& Luck, S. J. (2003). Serial deployment of attention during visual search. Journal of Experimental Psychology: Human Perception and Performance, 29, 121-138.

Worden, M. S., Foxe, J. J., Wang, N., \& Simpson, G. V. (2000). Anticipatory biasing of visuospatial attention indexed by retinotopically specific-band electroencephalography increases over occipital cortex. Journal of Neuroscience, 20, $1-6$.

Yamaguchi, S., Tsuchiya, H., \& Kobayashi, S. (1994). Electrooencephalographic activity associated with shifts of visuospatial attention. Brain, 117, 553-562.

Zanto, T. P., \& Gazzaley, A. (2009). Neural suppression of irrelevant information underlies optimal working memory performance. Journal of Neuroscience, 29, 3059-3066.

Zhang, W., \& Luck, S. J. (2008). Discrete fixed-resolution representations in visual working memory. Nature, 453, $233-235$.

Zokaei, N., Gorgoraptis, N., Bahrami, B., Bays, P. M., \& Husain, M. (2011). Precision of working memory for visual motion sequences and transparent motion surfaces. Journal of Vision, 11, 2.

Zokaei, N., Manohar, S., Husain, M., \& Feredoes, E. (2014). Causal evidence for a privileged working memory state in early visual cortex. Journal of Neuroscience, 34 , $158-162$. 